\title{
Impaired neurogenesis and associated gliosis in mouse brain with PEX13 deficiency
}

Rani Sadia Rahim ${ }^{1}$, James A. St John ${ }^{1,2,3}$, Denis I. Crane ${ }^{1 *}$, and Adrian C. B. Meedeniya ${ }^{3,4, *}$

${ }^{1}$ Griffith Institute for Drug Discovery, and School of Natural Sciences, Griffith University, Qld, Australia; ${ }^{2}$ Clem Jones Centre for Neurobiology and Stem Cell Research; ${ }^{3}$ Menzies Health Institute Queensland, Griffith University, QId, Australia, ${ }^{4}$ Interdisciplinary Centre for Innovations in Biotechnology \& Neurosciences, University of Sri Jayawardenepura, Nugegoda, Sri Lanka.

${ }^{*}$ Correspondence should be addressed to Dr Adrian Meedeniya, Menzies Health Institute Queensland, Parklands Drive, Griffith University, Southport, Gold Coast, Qld 4222, Australia / Interdisciplinary Centre for Innovations in Biotechnology \& Neurosciences, University of Sri Jayawardenepura, Nugegoda, Sri Lanka.Tel: (+940) 766864248; Fax: (+617) 37354255; Email: a.meedeniya@griffith.edu.au or Prof. Denis Crane, School of Natural Sciences, Griffith University, Nathan, Qld 4111, Australia. Tel: (+617) 37357253; Fax: (+617) 3735 7773; Email: d.crane@griffith.edu.au.

A. Meedeniya and D. Crane are equally contributing senior authors.

Keywords Zellweger syndrome, PEX13 mutant, brain development, neurons, glia, inflammation.

\section{Acknowledgements}

We thank Ahsan-ur-Rehman for assistance with image analysis software. This research was funded by Griffith University. The authors declare that they have no conflict of interest. 


\begin{abstract}
Zellweger syndrome (ZS), a neonatal lethal disorder arising from defective peroxisome biogenesis, features profound neuroanatomical abnormalities and brain dysfunction. Here we used mice with brainrestricted inactivation of the peroxisome biogenesis gene PEX13 to model the pathophysiological features of ZS, and determine the impact of peroxisome dysfunction on neurogenesis and cell maturation in ZS. In the embryonic and postnatal PEX13 mutant brain, we demonstrate key regions with altered brain anatomy, including enlarged lateral ventricles and aberrant cortical, hippocampal and hypothalamic organization. To characterize the underlying mechanisms, we show a significant reduction in proliferation, migration, differentiation, and maturation of neural progenitors in embryonic E12.5 through to P3 animals. An increasing reactive gliosis in the PEX13 mutant brain started at E14.5 in association with the pathology. Together with impaired neurogenesis and associated gliosis, our data demonstrate increased cell death contributing to the hallmark brain anatomy of ZS. We provide unique data where impaired neurogenesis and migration are shown as critical events underlying the neuropathology and altered brain function of mice with peroxisome deficiency.
\end{abstract}




\section{Introduction}

Zellweger syndrome (ZS) is a severe neonatal disease caused by mutations in peroxisome biogenesis $(P E X)$ genes which lead to loss of peroxisome biogenesis and peroxisomal metabolic function. ZS is a multi-system disorder with a prominent neurological component that features both neurodevelopmental deficits and neurodegeneration (Wilson et al., 1986). Brain abnormalities in ZS subjects, are generally considered to reflect neurodevelopmental defects, include growth retardation during embryonic stages, and neuronal migration defects that result in abnormal cerebellum gyration and cerebral cortex structure (Powers and Moser, 1998). These abnormalities are believed to reflect the importance of peroxisomes in brain development (Faust et al., 2005, Baes et al., 1997). In support of this premise, peroxisome abundance is high at neurite terminals of differentiating neurons during development, suggesting a role in neurite growth and synapse formation (McKenna et al., 1976, Arnold and Holtzman, 1978).

Peroxisomes play a role in the synthesis of plasmalogens, and therefore contribute to membrane stability and second messenger function, as well as being a major component of myelin sheaths (Brites et al., 2004), and docosahexaenoic acid (DHA), which has a significant role in neurotransmission, fine synaptic remodeling, and calcium homeostasis (Salem et al., 2001, Chapkin et al., 2009). These compounds also protect neurons from oxidative damage by scavenging reactive oxygen species (Braverman and Moser, 2012, Yavin et al., 2002). Peroxisomes are proposed as producing anti-inflammatory mediators in the brain (Farooqui, 2012, Farooqui et al., 2007) inferring a role in protecting newly differentiated neurons against oxidative stress and inflammation. Notably, despite these multiple roles for the peroxisome in brain physiology, it remains unclear how peroxisome deficiency causes the neuropathology of ZS.

PEX genes are required for the import of matrix and membrane proteins into the developing peroxisome (Distel et al, 1996; Gould and Valle, 2000). Mouse models of ZS have been generated by ubiquitous disruption of genes involved in peroxisomal matrix protein import - PEX2 (Faust and Hatten, 1997), PEX5 (Baes et al., 1997), and PEX13 (Maxwell et al., 2003). These mutants have ZS-like phenotypes that feature early neonatal death, neurological dysfunction, and associated peroxisomal metabolic dysfunction. 
To address ZS brain pathogenesis specifically, longer surviving PEX2 and PEX5 mutants (Faust, 2003, Faust and Hatten, 1997, Dirkx et al., 2005), and mouse mutants with brain-restricted PEX gene deficiency, have been examined. These studies have demonstrated that PEX gene deficiency leads to prominent neuronal migration defects, abnormal cerebellum and cerebral cortex cytoarchitecture, demyelination, inflammation, and motor dysfunction (Hulshagen et al., 2008, Krysko et al., 2007, Bottelbergs et al., 2012, Muller et al., 2011, Janssen et al., 2000).

The present study focuses on mouse mutants in which PEX13 is selectively deleted in of all neuronal lineage cells (PEX13 brain mutant). PEX13 brain mutants have been previously shown to have abnormal neurodevelopmental features that include altered Purkinje cell differentiation and the formation of the granule cell layer in the cerebellum (Muller et al, 2011). More recently we have also demonstrated significant deficiency of the serotonergic system in these mutants (Rahim et al, 2014). Importantly, PEX13 mutations in humans give rise to clinical phenotypes in the Zellweger spectrum (Shimozawa et al., 1999, Liu et al., 1999), thus PEX13 brain mutants provide a valid animal model to address the neurodevelopmental changes of ZS.

In the present investigations, we used the PEX13 brain mutants to investigate the effect of PEX13 deficiency on neurogenesis, differentiation and migration, and associated pathophysiological and anatomical changes. Our findings indicate significant changes to neurogenesis and neuronal migration, and concomitant gliosis together with increased cell death, which in toto may provide an explanation of the mechanisms underlying the brain pathophysiology of ZS. 


\section{Methods and materials}

\section{Generation of PEX13 brain mutants}

Animal breeding and experimentation were approved by the Griffith University Institutional Biosafety Committee (NLRD/21/07) and the Griffith University Animal Ethics Committee (BBS/02/09/AEC; ESK/03/13/AEC), respectively.

Brain-specific disruption of PEX13 was achieved using Nestin-Cre transgenic mice (Nes-Cre/+) in which Cre recombinase is expressed in cells of neuronal lineage under the control of the nestin promoter and intron 2 enhancer (Tronche et al., 1999; Zimmerman et al., 1994). To produce sufficient excision, PEX13 heterozygotes $\left(P E X 13^{N /+}\right)$ were crossed with Nes-Cre/+ transgenic mice to generate Nes-Cre, PEX $13^{N /+}$ mice. These mice were then crossed with $P E X 13^{\text {flox } f l o x}$ mice to generate mice with brain-specific disruption of PEX13 (PEX13 /floX ${ }^{\triangle}$ mice, or, simply, PEX13 brain mutants). Because this breeding strategy does not generate wild-type progeny, we have designated 'effective' wild-type (WT) animals as those animals that exhibit no disease phenotype and carry one wild-type allele and one PEX13 flox allele (but no Cre transgene); these animals were treated as littermate controls (and designated as WT mice) for these studies.

PEX13 gene disruption was assessed using PCR of mouse brain genomic DNA. To support the DNA analyses, PEX13 protein deficiency was confirmed by immunofluorescence staining of brain tissue sections using the antibody to PEX13.

\section{EdU labelling, tissue harvesting and processing}

To determine cell proliferation in embryos and postnatal pups, 5-ethynyl-20-deoxyuridine (EdU), dissolved in Dulbecco's phosphate buffered saline (D-PBS), was injected into time-mated pregnant mice at a dose of $50 \mathrm{mg} / \mathrm{kg}$ body weight, to label the DNA of dividing cells in the developing brain. For the analysis of neurogenesis, two pregnant dams at each of the embryonic stages E12.5, E14.5 and E18.5 received a single intraperitoneal injection of EdU. The dams were sacrificed $4 \mathrm{~h}$ following the EdU injection, as described a terminal dose of a ketamine/xylazine mixture $(80 \mathrm{mg} / \mathrm{kg}$ body weight ketamine $/ 10 \mathrm{mg} / \mathrm{kg}$ body weight xylazine) was administered via intraperitoneal injection, the embryos removed through midline abdominal section, and the embryonic brains drop-fixed in Zambonie's fixative overnight under vacuum. 
Two litters of mice at postnatal stage P0 similarly received a single intraperitoneal injection and were sacrificed $4 \mathrm{~h}$ later.

To evaluate postnatal cell migration, we injected four cohorts of P0 pups with EdU (50 mg/kg i.p) at birth. Brains from two of these cohorts were harvested after $4 \mathrm{~h}$ (designated $\mathrm{P} 0$ ) and the remaining two cohorts after 3 days (designated P3). The pups were perfused transcardially with $10 \mathrm{mM}$ phosphatebuffered saline, $\mathrm{pH} 7.4$ (PBS) containing $0.5 \%$ sodium nitrite to flush out the blood, followed by perfusion with modified Zambonie's fixative reagent (2\% paraformaldehyde, $0.2 \%$ picric acid, $0.1 \mathrm{M} \mathrm{PBS}, \mathrm{pH} 7.2$ ). The brains were subsequently removed and placed overnight in the same fixative under vacuum at room temperature.

To calculate serotonergic neurogenesis and cell specification in postnatal stages, we applied three EdU experimental strategies: (1) to label serotonergic progenitors cells: EdU was injected at E9.5E10.5 stage (in mice, progenitors give rise to serotonergic neurons in the ventral rhombencephalon between E9.5 and E11.5 stages (Deneris and Wyler, 2012)) and harvested at the P0 stage; (2) To label cells that undergo division during serotonergic cell specification:EdU was injected at embryonic stages E12.5 and E14.5 and the brains harvested after $4 \mathrm{~h}$; (3) to label cells at the end of serotonergic neurogenesis: EdU was injected at E12.5-E13.5 (end of serotonergic neurogenesis) and harvested at the P15 stage; the P15 animals were perfusion-fixed as above and the brains harvested.

Brain tissue was collected and processed for cryosectioning using O.C.T. compound (Tissue-Tek; Sakura Finetek, USA, Inc) embedment using a sucrose gradient as described previously (Norazit et al., 2011, Nguyen et al., 2010). Brains were mounted in 100\% OCT and sections were cut on a cryostat at a thickness of 20-40 $\mu \mathrm{m}$ and mounted on superfrost slides. E12.5 to E18.5 embryonic stages for sectioning were selected using a prenatal mouse brain atlas (Schambra, 2008). The Paxinos rodent brain atlas was used to select sections from P0 and P15 stages (Paxinos and Franklin, 2001). Immunofluorescence analysis of neurodevelopmental events - neurogenesis, proliferation, differentiation, migration and cell specification - a minimum 10 sections were selected at periodic intervals from the ventricular zone (VZ) area at embryonic stages E12.5 and E14.5, and from the sub-ventricular zone (SVZ) at E18.5 and P0. 
For serotonergic cell specification analysis, a minimum of 10 sections were selected from the isthmus region at each stage (E12.5, E14.5, P0 and P15).

\section{EdU click chemistry and immunofluorescence analysis}

For the EdU click chemical reaction, brain sections were treated as described earlier (Chehrehasa et al., 2009): brain sections were permeabilized with $0.2 \%$ Triton X-100/PBS (wash buffer) for 20 min then incubated with $100 \%$ DMSO for $15 \mathrm{~min}$ at room temperature, followed by further washes with washing buffer to remove DMSO. Brain sections were then incubated with Click-iT reaction master mix for $45 \mathrm{~min}$ in the dark. For immunostaining, Click-iT reaction master mix was removed and the sections washed with buffer for $30 \mathrm{~min}$ and incubated in blocking buffer (PBS/0.1\% Triton X-100 containing $10 \%$ donkey serum $(\mathrm{v} / \mathrm{v}))$ for $1 \mathrm{~h}$ at room temperature to block non-specific tissue binding sites. Multiple combinations of primary antibodies were used: mouse anti-GFAP, (1:800,Sapphire Biosciences); rabbit anti-GFAP, (1:800, Merck-Millipore); rabbit anti-lba-1, (1:2000, Wako Chemicals); goat anti-lba-1, (1:500, Abcam); goat anti-TPH2, (1:750, Everest Biotech); rabbit anti-Tph2, (1:750, ThermoFisher Scientific, Inc. Rockford, IL, USA); rabbit anti- $\beta$-III tubulin (or Tuj-1), (1:1000, ThermoFisher Scientific); mouse anti-NeuN, (1:100, Merck-Millipore); rabbit anti-Ki67, (1:200, Cell Signalling Technology); and rabbit anti-cleaved caspase3, (1:400, Cell Signalling Technology). Antibodies were diluted in blocking buffer and incubated with sections overnight at $4^{\circ} \mathrm{C}$. Sections were then washed a minimum of four times in PBS/Triton and incubated with the appropriate Alexa Fluor-conjugated secondary antibodies and Hoechst nuclear marker diluted in PBS/Triton, for $3 \mathrm{~h}$ at room temperature - donkey anti-rabbit 488 or 594 (1:400; Life Technologies); donkey anti-goat 594 or 488 (1:400, Invitrogen); donkey anti-goat 650, 1:50 (Abcam); donkey anti-mouse 594 (1:800; Life Technologies). After incubation with secondary antibodies, the sections were washed in PBS/Triton and mounted using DAPI anti-fade mounting media (Vectashield) and cover-slipped.

\section{Image acquisition}

Images were acquired using an Olympus FV1000 laser scanning confocal microscope (Olympus).

For cell morphology and cell-cell contact analysis Z-stack images of 0.1-0.2 $\mu \mathrm{m}$ optical planes were acquired. For comparison of immunofluorescence intensity, images were captured using constant image- 
acquisition parameters. For brain morphology, total cell count and cell distributional analysis, images were also captured at lower magnifications (4X and 10X) using constant image-acquisition parameters on an Olympus FV1000 confocal microscope and a Olympus BX50 microscope with a SPOT camera (Diagnostic Instruments). Z-stack images were further processed and analysed using ImageJ software. Figures were assembled using Inkscape software.

\section{Analysis of brain morphology}

For gross morphological analysis of the whole brain of embryos and postnatal stage animals, images were captured and brain size was measured using longitudinal dimensions with the scaling option in FV1000 microscope and Inkscape software. For other morphological parameters i.e. cerebral cortex thickness and lateral ventricle distensions, brain samples were sectioned as $20-40 \mu \mathrm{m}$ thick serial coronal sections through the anterior telencephalon, immediately mounted onto superfrost slides (Thermo Scientific), and stained with $1 \% \mathrm{w} / \mathrm{v}$ Nissl stain to allow matching of sections through reference to the prenatal mouse brain atlas for embryonic stages and the Paxinos rodent brain atlas for postnatal stages. Cell nuclei in all sections were stained using $1.5 \mu \mathrm{g} / \mathrm{mL}$ DAPI anti-fade mounting media (Vectashield) (Ka et al., 2014). Images were captured at $4 X$ and 10X using an Olympus BX50 microscope and SPOT camera or an Olympus FV1000 confocal microscope. Neocortical thickness was calculated from the corticostriatal edge to the dorsomedial tip beside the lateral ventricle.

\section{Cell identification and quantification}

For all quantifications, comparisons between WT and mutants used z-stacks of the same depth. Quantification of general neurogenesis/progenitor proliferation, neuronal and glial differentiation were carried out by counting total numbers of EdU labelled cells and Ki67, Tuj-1, GFAP and Iba-1 immunoreactive cells, respectively. Cells were counted in $20 \mu \mathrm{m}$ thick brain sections with $200 \mu \mathrm{m}$ periodic intervals throughout the whole telencephalon volume. Further z-stacks images with 0.1-0.2 $\mu \mathrm{m}$ thin optical slices were captured at 10X magnification, a confocal microscope and then analyzed using ImageJ software (National Institutes of Health, Bethesda, USA; ITCN plugin). 
EdU labelling and Ki67 immunolabelling were used to assess cell proliferation dynamics. Cells were counted from the VZ to the cortical plate (CP) across the entire section, and in the SVZ. Cell counts per $\mathrm{mm}^{2}$ area were estimated separately at higher magnification using a cell counter (ImageJ ITCN plugin).To evaluate the stage of differentiation of progenitors into neurons, the total number of Tuj-1+ cells (marker of differentiating neurons) relative to the total number of cells (DAPI labelled nuclei) in the VZ to the CP area were measured. Similarly, EdU+/Tuj-1+ cells (indicating newborn progenitors directly differentiated into neurons) and EdU+/Tuj-1-cells (indicating the number of intermediate progenitors, neuroblasts or glia) were counted.

For serotonergic neurogenesis and cell specification analyses, the total number of EdU-labelled cells were counted to determine the number of progenitors undergoing cell division at E9.5-E10.5 stage; time of EdU pulse and the number that had migrated to the midbrain at the P0 stage (time of harvest) using $4 \mathrm{X}$ images of the midbrain region, using ITCN plugin. In addition, the number of EdU+/ TPH2+ cells as a proportion of the number of $\mathrm{TPH} 2+$ cells at the isthmic part of dorsal raphe nucleus (isDRd) and reticular tegmental nucleus of the pons $(\mathrm{RtTg})$ area of the isthmus were counted to estimate serotonergic cell genesis during the EdU pulse period. At P15 stage, the number of TPH2+/NeuN+ cells was counted to measure the number of serotonergic progenitors which had differentiated into mature neurons and migrated towards the midbrain raphe nuclei (at least 10 sections per animal; $n=3$ animals for both wildtypes and PEX13 brain mutants of all neurodevelopmental and postnatal stages). To estimate the level of apoptosis at each stage (E12.5, E14.5, E18.5 and P0), the total number of apoptotic cells (labelled with CC3 antibody and having a nucleus with pyknotic appearance) were counted for the VZ and isthmus regions, using ImageJ.

\section{Analysis of gliosis and glial morphology in early development}

For the estimation of neuroglial cell proliferation and neural progenitor differentiation into non neuronal cells, EdU+/GFAP+ cells and EdU+/lba-1+ cells per $\mathrm{mm}^{2}$ area were counted in the VZ/SVZ, meninges and dentate gyrus (DG) areas at high magnification by means of a cell counter (ImageJ plugin).

Glial morphology was analysed from Z-stacks images of the SVZ and DG areas at 60X (oil immersion objective; na 1.4) using the confocal microscope. In this analysis microglia were categorized 
as "resting", "activated", or "phagocytic" using previously described criteria (Norazit et al., 2011, Kreutzberg, 1996). The thickness of astroglial processes and their immunofluorescence intensity were also analyzed using ImageJ (6 sections per animal).

To evaluate glial interactions with apoptotic cells, we scored microglia-enfolded cells with evidence of phagocytosis (dead cellular components i.e. pyknotic nuclei fragment in microglial cytoplasmic pouch). For these analyses, coronal sections of the telencephalon were immunostained with GFAP (astrocyte marker), Iba-1 (microglial marker), cleaved caspase-3 antibody (apoptosis marker), EdU (to label S-phase DNA) and DAPI (to label nuclei). Z-stack images were captured of $0.25 \mu \mathrm{m}$ thick series of 100 optical slices using the $60 \mathrm{X}$ oil immersion objective, and upper and lower threshold levels were estimated by means of the spatial Image series setting. Further Z-stack images were reconstructed in 3D using Imaris Bitplane Scientific Software (Zurich, Switzerland). Glial cell Interactions with apoptotic cells or progenitors were defined by the co-localization of two fluorophores, such as Iba-1 and cleaved caspase-3 in $0.25 \mu$ m-thick optical slices.

We assessed the number (per $\mathrm{mm}^{2}$ area) of glial interactions with, and phagocytosis of, apoptotic cells and EdU labelled apoptotic cells in each section for each embryonic stage: A, EdU labelled cells or apoptotic cells encircled with microglial processes either loosely or tightly; B, microglia-phagocytosed apoptotic cells (pyknotic appearance on DAPI staining) within a microglial cytoplasmic pouch; C, microglia-phagocytosed EdU-labelled cells, or EdU labelled DNA fragments observed in microglia cytoplasm.

\section{Analysis of cell migration and distribution of progenitor cells}

For comparative analysis of radial and tangential migration, two areas of the SVZ were selected the dorsal roof (drSVZ) to measure glial proliferation, and the dorso-lateral region (dISVZ) to measure neuronal progenitor proliferation. Fluorescence and differential interference contrast (DIC) microscopic images were captured at 40X on matched sections of the SVZ area of the telencephalon of P3 and P0 animals, using the confocal microscope with a set exposure time. For comparative analysis of progenitor migration from the SVZ to the intermediate zone (IZ) for stage P0 (4 h EdU exposure) animals and P3 
animals (injected at PO and harvested after 3 days), the number of EdU+ migratory progenitor cells (Rakic, 1985, Ono et al., 1997) were counted for the SVZ using ImageJ software and the ITCN plugin. Distributional analyses of proliferating and migrating cells were estimated by counting the number of EdU+ cells in the VZ and the SVZ/IZ at each stage. For migration analysis at postnatal stage P15, two pregnant dams were injected with EdU at E12.5-E13.5 stages and harvested as P15. EdU was labelled with Alexa fluor 488 and the number of EdU+ cells was counted in an area of $450 \mu \mathrm{m}$ by $450 \mu \mathrm{m}$ across the cortex, which was divided into six equal width counting regions (a-f), with the length of cortex identified using DAPI staining (Ka et al., 2014).

\section{Densitometric measurements}

To measure immunofluorescence intensity for GFAP, EdU, and Tuj-1 antibodies staining in the telencephalon of the brain, images were captured using constant image acquisition parameters to allow comparison of matched specimens, and fluorescence intensity was quantified using ImageJ following conversion to grey scale. Background fluorescence was set on a region lacking detectable fluorescence.

\section{Statistical analyses}

Statistical comparison between groups (wild-type vs brain mutant) was carried out using the Student's ttest. 


\section{Results}

\section{PEX13 brain mutants display abnormal gross brain anatomy}

We analyzed gross anatomical changes of the brain over a range of developmental periods from early to late embryonic stages (E12.5, E14.5 and E18.5), at P0, and at P15. We also analysed nuclear (DAPI) stained sections of brain regions identified as the primary neurogenic zones i.e. cortical ventricular zone $(\mathrm{VZ}) /$ neuroepithelium of neocortex in embryonic stages, and the sub-ventricular zone (SVZ) and the dentate gyrus (DG) in postnatal stages (Altman, 1969, Altman, 1963), over these same periods to assess gross morphological changes. The brains of the mutant mice were significantly smaller than those of wildtype mice at all stages tested (Fig. 1a, b). 
a
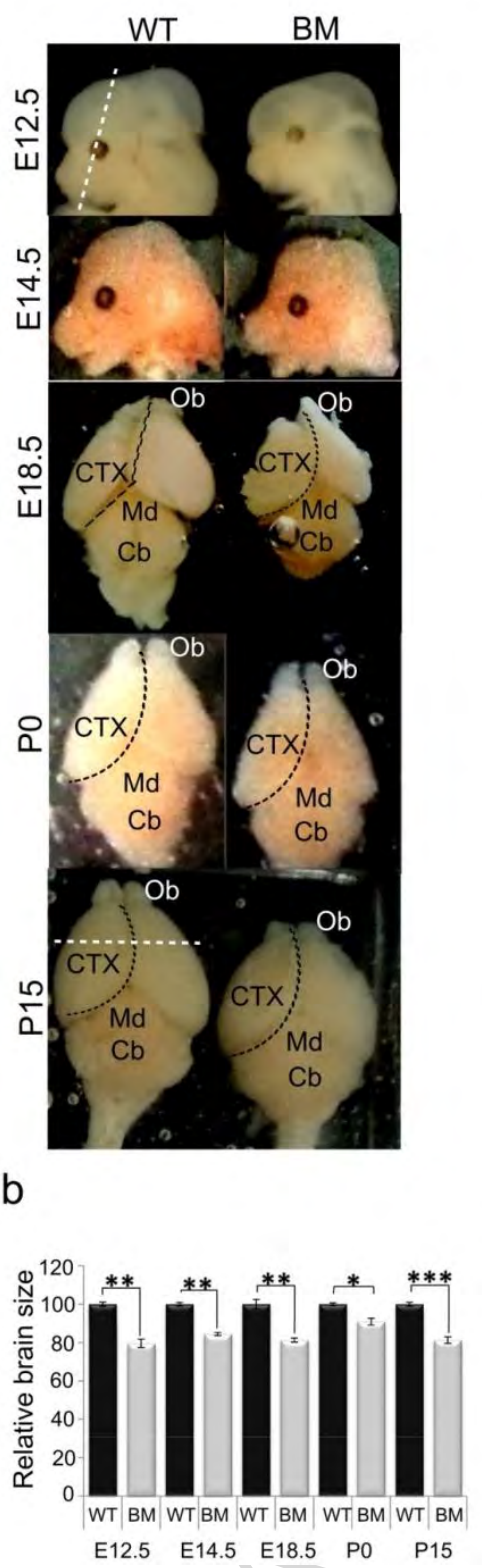

C
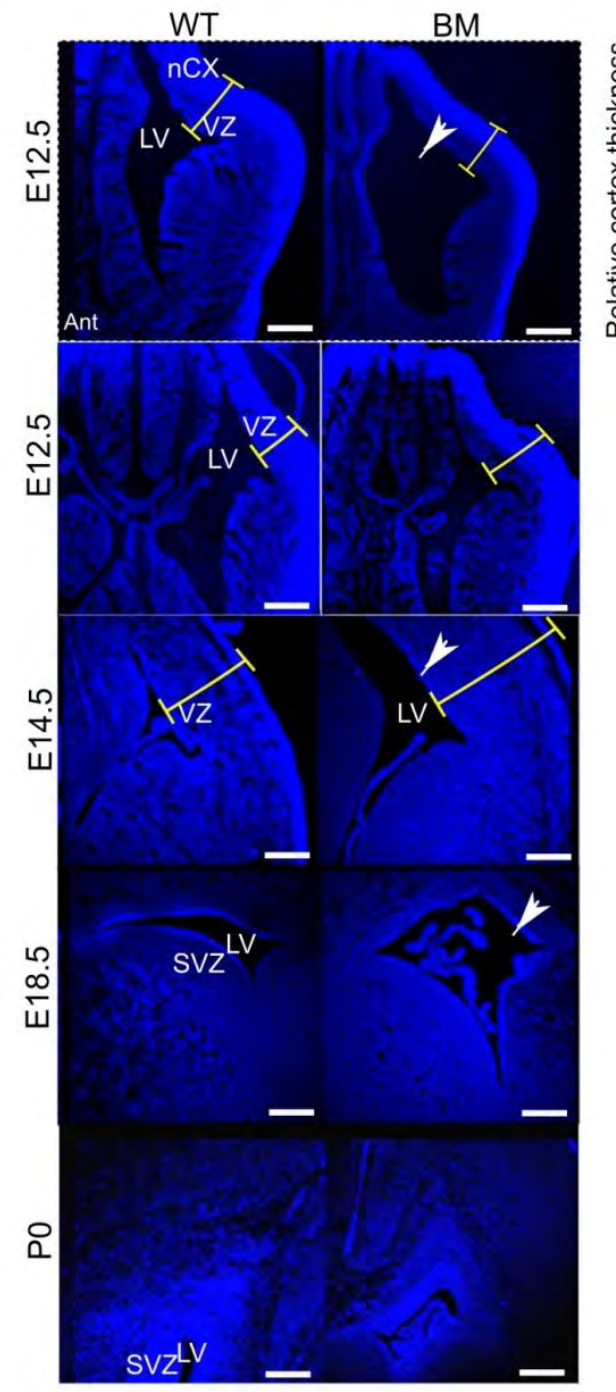

d

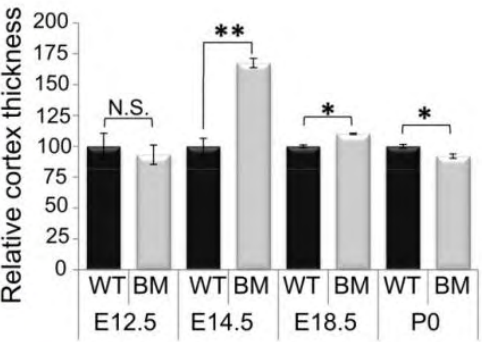

Fig. 1. PEX13 deficiency leads to abnormal brain morphology. (a) The top two panels provide a lateral head view of E12.5 and E14.5 embryos; the dotted white line demarcates the sampling plane. The remaining panels provide dorsal views of the brain from E18.5 to P15. (b) Relative brain size of the BM compared to the WT from E12.5 to P15. (c) Coronal sections of each stage indicating dilated and enlarged lateral ventricles (arrowheads), abnormal cerebral cortex (yellow line). Scale bars $200 \mu \mathrm{m}$. (d) The cerebral cortex was variable in thickness in the embryonic stages, but was reduced in thickness at birth (P0). Ant, anterior telencephalon; BM, PEX13 brain mutant; Md, midbrain; Cb, cerebellum; CTX, cerebral cortex; GE, ganglionic eminence; LV, lateral ventricles; nCX, Neocortex; Ob, olfactory bulb; SVZ, 
subventricle zone; VZ, ventricles zone; WT, wild-type. Data represent mean \pm SEM for 3 animals for both WT and PEX13 brain mutant mice. ${ }^{*} p<0.05,{ }^{* *} p<0.01$.

The mutants also showed a reduction in the size of the olfactory bulbs (Fig. 1a). Analysis of matched DAPI-stained sections (Fig. 1c) indicated further changes: substantial enlargement of the most frontal aspects of the cortex at E14.5 - becoming less evident at E18.5 and P0 - and enlarged lateral ventricles in the telencephalon area from the E14.5 stage through to the P0 stage (Fig. 1c), and up to P15 (data not shown). We also measured the thickness of the cerebral cortex. In wild-type animals, cortical thickness, analysed using serial sections, gradually increased more laterally. In contrast, cortical thickness for the mutants was irregular along the mediolateral axis of the neocortex, i.e. very thin dorsally, but thicker at the lateral side (Fig.1c, d), suggesting disorganization of the telencephalon area. Dilatation of ventricles and apparent subsequent pressure to the frontal aspects of the telencephalon caused a dome-shaped appearance of the cerebral cortex at the E18.5 stage of mutants, despite the increased cerebral cortex thickness (Fig. 1c). The cerebral cortex was extended in the telencephalon region at the E14.5 and E18.5 stages (data not shown). Importantly, similar aberrant anatomy of the cortex and lateral ventricles have been described for neonatal ZS patients (Nakai et al., 1995). These findings of a significant alteration in brain morphology in the PEX13 brain mutant, suggest a defect in brain development, either as a defect in cell proliferation, differentiation, migration or cell death.

\section{Impaired neurogenesis}

To assess proliferative cells during early embryonic stages, the neuroepithelium of the neocortex (VZ) was selected. For analysis of late embryonic and postnatal stages, two neurogenic zones - the SVZ and the DG - were selected. Within the SVZ, the dorsal roof of the SVZ (drSVZ) and the dorso-lateral SVZ (dISVZ) were selected for progenitor proliferation analysis at later ages. The drSVZ is a region with a heterogeneous population of predominantly proliferating glia. The dISVZ is a region of predominantly proliferating neuronal progenitors. Analyses were first undertaken for cells in the entire region 
encompassed by the ventricular zone (VZ), the sub-ventricular zone (SVZ), the intermediate zone (IZ) and the cortical plate (CP). Separate measurements were also carried out on the VZ for early embryonic stages and SVZ for late embryonic and postnatal stages as these represent active neurogenic pools of differentiating and migrating cells (Altman, 1969, Lois and Alvarez-Buylla, 1994, Doetsch and AlvarezBuylla, 1996, Paridaen and Huttner, 2014, Taverna et al., 2014). This analysis was carried out using the cell proliferation marker 5-ethynyl-20-deoxyuridine (or EdU) (Chehrehasa et al., 2009), which tags cells in the S-phase of the cell cycle. Tissues were harvested $4 \mathrm{~h}$ post-EdU injection. The EdU data were validated with immunofluorescence labelling for Ki67, a transcription factor that is expressed in all active phases of the cell cycle (Gerdes, 1990). 


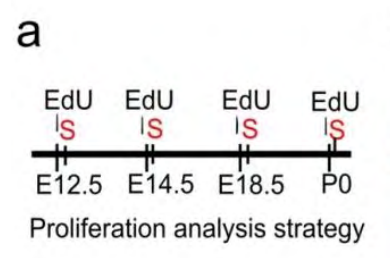

b

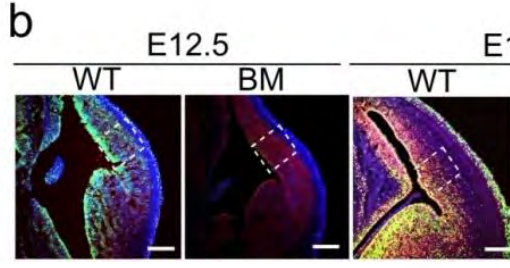

Fig 2

C

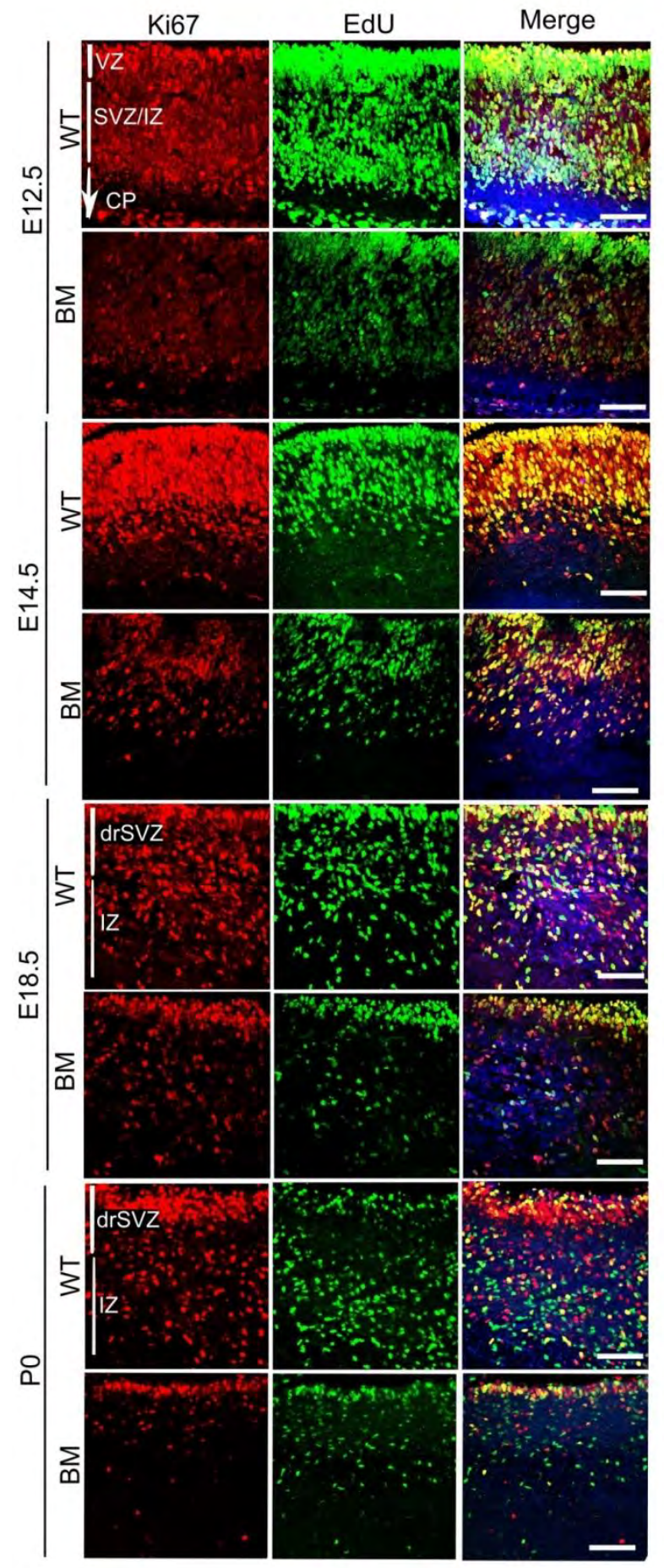

d

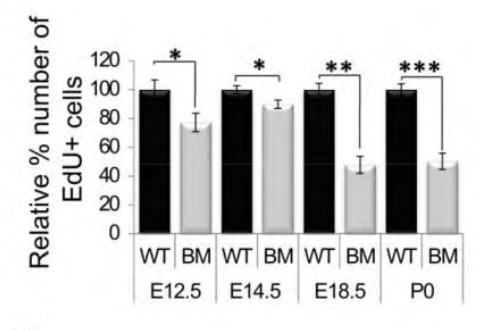

e
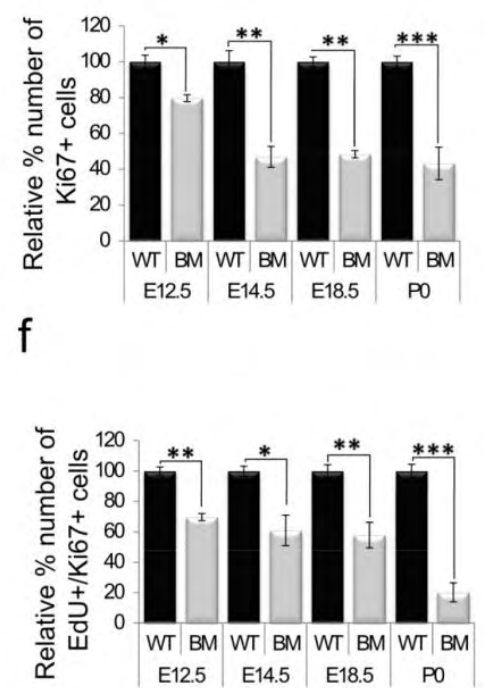

g

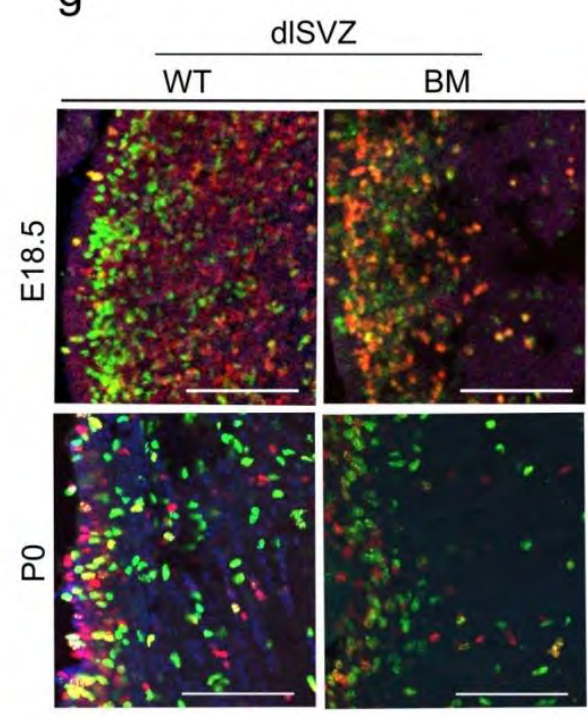


Fig. 2. PEX13 deficiency leads to reduced rates of cell proliferation in the SVZ. (a) To assay stem and progenitor cell proliferation across the developmental stages E12.5-P0, EdU was injected $4 \mathrm{~h}$ before the animals were sacrificed (S). (b, c) Cell proliferation in the SVZ was analysed by click-labelling for EdU (green) and immunofluorescence labelling for Ki67 (red) on coronal sections from E12.5 to P0. Cell nuclei were stained with DAPI. Images in panel $C$ represent those from sampling the drSVZ region demarcated by the dotted boxes in panel b. The arrow (E12.5 image) depicts the expected direction of cell migration from the VZ to the CP. Scale bars: $200 \mu \mathrm{m}$ (panel b), $100 \mu \mathrm{m}$ (panel c). (d) The number of EdU-positive cells, (e) the number of Ki67-positive cells and (f) The number of EdU+/Ki67+ cells in the VZ to CP region in early embryonic stages, and in the SVZ (drSVZ and dISVZ) in E18.5 and P0 stages, are presented as a percentage of the number of cells in the wild-type animals. (g) A high magnification view of the dISVZ region at the E18.5 and P0 stages demarcated by dotted boxes in panel b. Scale bar, $25 \mu \mathrm{m}$. CP, cortical plate; IZ, intermediate zone; SVZ, subventricular zone; VZ, ventricular zone; dISVZ, dorso-lateral subventricular zone; drSVZ, dorsal roof of sub ventricular zone; WT, wild-type; BM, PEX13 brain mutant. Data are expressed as the mean \pm SEM for 3 animals for both WT and PEX13 brain mutant mice. ${ }^{*} p<0.05,{ }^{* *} p<0.01,{ }^{* * *} p<0.001$.

We carried out these analyses at stages E12.5 and E14.5 (where neurogenesis is at its peak), E18.5 (end of neurogenesis) and at P0 (early postnatal stage) (Bayer et al., 1991) (Fig. 2a).

Our analyses included counting the number of cells that were: 1) EdU+ (as a measure of the number in S-phase, or DNA synthesis), 2) Ki67+ (at any active stage in the cell cycle, or proliferation phase), 3) EdU+/Ki67- cells (that underwent DNA synthesis but which have exited the cell cycle $4 \mathrm{~h}$ later, 4) EdU+/Ki67+ (those in both DNA synthesis and proliferation phases), and 5) EdU-/Ki67+ (those that have not undergone DNA synthesis but are in the proliferation phase.

The results obtained for the mutants showed a substantial decrease in the relative number of cells that were undergoing proliferation, as measured by both EdU and Ki67 labelling across the entire VZ-CP region at all stages tested (Fig. $2 \mathrm{~b}-\mathrm{c}$ ). In addition, for the mutants, many more of the cells that were EdU labelled were Ki67 negative at the VZ (see Supplementary Fig. S1), indicating that these cells had initiated proliferation, but had prematurely exited the proliferation cycle.

Proliferating cells in the VZ divide asymmetrically to produce intermediate progenitors that migrate towards the next proliferating zone, the SVZ (Zecevic et al., 2005, Haubensak et al., 2004, Noctor 
et al., 2004). In addition, the SVZ continues neurogenesis at later embryonic stages (Zecevic et al., 2005, Haubensak et al., 2004, Noctor et al., 2004). To provide a measure of cell proliferation at the late E18.5 embryonic and P0 postnatal stages, EdU+ and Ki67+ cells were counted in the dISVZ (where the predominant pathway is proliferation of neuronal progenitors into neuroblasts) and in the drSVZ (proliferation of glial from radial glial daughter cells). By the E18.5 and P0 stages, wild-type mice showed significant numbers of dividing progenitors (EdU labelled) in the drSVZ and dISVZ (Fig. 2c, g). Neuronal progenitor proliferation at the dISVZ is also illustrated at higher magnification of dotted boxes in panel B as Fig. 2g. In contrast, PEX13 brain mutant had reduced numbers of EdU+ and Ki67+ cells in both the drSVZ and dISVZ regions (Fig. 2c, g). This finding points to a significant decrease in cell proliferation in the mutant brain. Overall, these results show a reduction in cell genesis, either due to a reduction in the population of dividing progenitors, or to protracted cell cycle periods or intermediate progenitor migration. These findings are consistent with the smaller brains of the PEX13 brain mutants.

The second part of these analyses focused on the dentate gyrus (DG) region of the hippocampus, another neurogenic zone in the adult brain where progenitors undergo division, differentiation and migration (Altman, 1963, Altman and Bayer, 1990). We investigated neurogenesis using the EdU/Ki67 double labelling approach as before. In comparison to wild-type mice, PEX13 brain mutants showed significantly lower numbers of EdU+ cells, Ki67+ cells, and EdU+/Ki67+ cells in the DG at P0 (Fig. 3a-d), indicating substantially reduced cell genesis and/or cell proliferation.

a

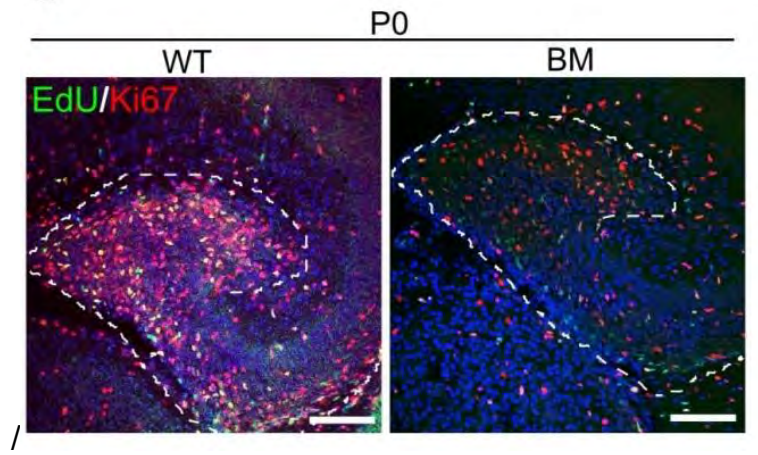

b

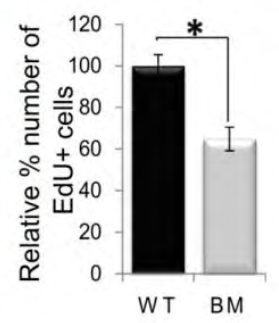

C

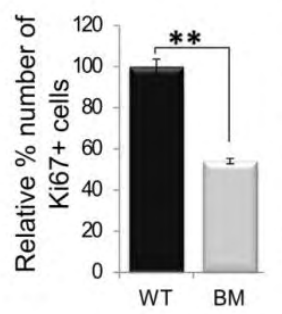

d

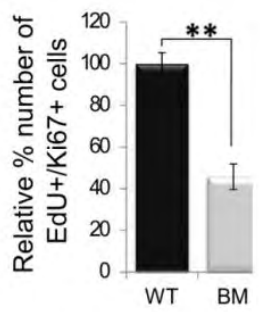


Fig. 3. PEX13 deficiency leads to reduced cell proliferation in the dentate gyrus. Stem and progenitor proliferation in DG was analyzed by EdU labelling (green), and validated using immunofluorescence for Ki67 (red) on coronal sections from P0 mice. DAPI was used to label cell nuclei. (a) Progenitor proliferation in the dentate gyrus (DG) of the hippocampus assessed by sampling the region demarcated by the dotted line. Scale bar $100 \mu \mathrm{m}$. (b, c, d) The number of the EdU+ cells, Ki67+ cells, and $\mathrm{Ki67+/EdU+} \mathrm{cells,} \mathrm{respectively,} \mathrm{in} \mathrm{the} \mathrm{dendate} \mathrm{gyrus} \mathrm{of} \mathrm{the} \mathrm{PEX13} \mathrm{brain} \mathrm{mutants} \mathrm{relative} \mathrm{to} \mathrm{wild-type}$ mice.

\section{Altered neurogenesis and gliogenesis at sequential developmental time-points}

\section{(a) Altered neuronal differentiation}

Progenitors undergo mitosis at the VZ to generate intermediate progenitors which then migrate from the ventricular surface to the SVZ. In the SVZ, further division results in the generation of pairs of intermediate progenitors or nascent neurons, which migrate to their final positions (Noctor et al., 2004, Haubensak et al., 2004, Taverna et al., 2014). Projection neurons in the cerebral cortex are produced and differentiate in the ventricular zones and migrate radially to the overlying cortical plate (Kowalczyk et al., 2009). Cortical interneurons are produced at the ganglionic eminence and then migrate tangentially to the cortex (Tamamaki et al., 1997). The data for EdU labelling and EdU/Ki67 co-labelling for the PEX13 brain mutants presented in Fig. 2 indicates reduced cell proliferation and a reduction in the number of cells that undergo further differentiation in the SVZ.The data for EdU labelling and EdU/Ki67 co-labelling presented in Fig. 2 suggest that PEX13 brain mutants have reduced cell proliferation and a reduction in the numbers of cells that are undergoing further differentiation in the SVZ. In this next approach, we co-immunolabeled coronal sections (Fig. 4a) for Tuj-1 (using $\beta$-III tubulin antibody), an early marker of differentiating and mature neurons (Brazelton et al., 2000), in combination with EdU labelling, to label neurons that have arisen from intermediate progenitors. 
Fig 4

a

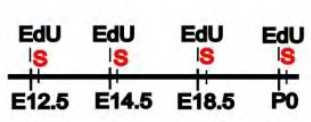

Neuronal differentiation analysis strategy

C

b
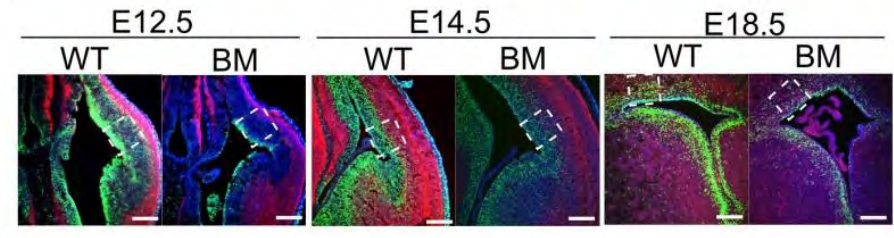

d

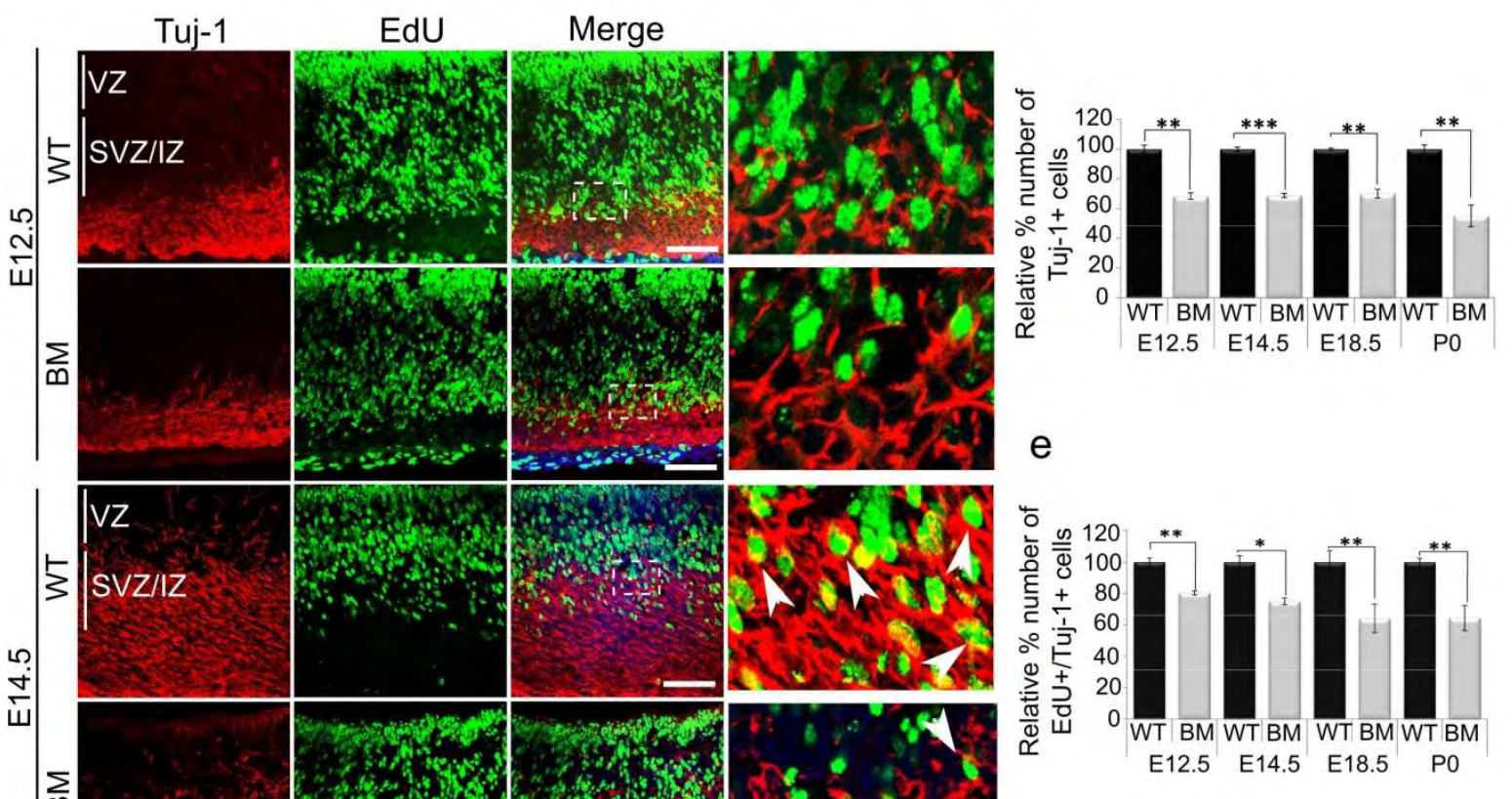


Fig. 4. PEX13 brain mutants show impaired neuronal maturation and reduced neurogenesis in the SVZ. (a) Experimental strategy for EdU-based analysis of neuronal differentiation, with EdU injected $4 \mathrm{~h}$ before the animals were sacrificed. (b) Coronal sections from E12.5, E14.5, E18.5 embryonic and P0 stages were immuno-labelled with Tuj-1 antibody, a marker of mature and differentiating neurons (red), EdU (Sphase DNA, green), and DAPI (nuclei, blue) for analysis of neuronal differentiation by stem cells in the SVZ of the telencephalon. Scale bars $200 \mu \mathrm{m}$. (c) Magnified images through the SVZ (indicated by dotted regions) of the broad views in panel b. Scale bars $50 \mu \mathrm{m}$. The right panels represent magnified images of the areas demarcated by the dotted regions in the "Merge" images, where EdU labelled, Tuj-1+ cells are indicated by white arrowheads. (d) The number of Tuj-1+ neurons in the cerebral ventricular zone at each stage, expressed relative to numbers for wild-type mice. (e) The number of EdU+/Tuj-1+ cells in the $S V Z / I Z$ area expressed relative to those for wild-type mice. IZ, intermediate zone; SVZ, subventricular zone; VZ, ventricular zone; WT, wild-type; BM, PEX13 brain mutant. Data represent the mean \pm SEM for 3 animals for both WT and PEX13 brain mutant mice. ${ }^{*} p<0.05,{ }^{* *} p<0.01^{* * *}, p<0.001$, compared to WT.

Analysis of wild-type mice demonstrated the expected pattern of Tuj-1 immunostaining from E12.5 to P0 (Fig. 4b, c) (Sakurai et al., 2006, Nishino et al., 2013, Iwashita et al., 2014). For the mutants, we demonstrated a reduced number of Tuj-1+ cells (and reduced Tuj-1 fluorescence per cell) in mutant brain at all stages tested (Fig. 4b, c): at the E12.5, E14.5 and E18.5 stages, the number of Tuj-1+ cells was approximately $70 \%$ of that for wild-type mice, and declined to $55 \%$ at the P0 stage (Fig. 4c, d). In the SVZ area, intermediate progenitors generate cortical neurons largely through symmetrical, and to a lesser degree through asymmetrical mitosis (Noctor et al., 2004, Haubensak et al., 2004, Gal et al., 2006). Compared to wild-type mice, the mutants showed a progressive decline in the number of EdU+/Tuj-1+ cells in the SVZ/IZ area from E12.5 to the P0 stage (Fig. 4c, e), indicating that fewer intermediate progenitors differentiated into neurons. The EdU+/Tuj-1- cells represent intermediate progenitors (proliferating cells) at early embryonic stages. These results, together with those presented in Fig. 2 suggest that the mutants have a reduced number of proliferating cells which differentiate into mature neurons and/or have delayed migration from the VZ to the SVZ/IZ. 


\section{(b) Increased gliosis}

We have previously reported that PEX13 brain mutants display a neuroinflammatory phenotype at postnatal stages (Muller et al., 2011, Rahim et al., 2014). To determine whether the observed changes to neuronal differentiation in these mutants were associated with glial proliferation/reactive gliosis in early neurodevelopment, we carried out cell-specific immunofluorescence analyses of the SVZ from stages E12.5 through to P0 to detect glial fibrillary acidic protein (GFAP), an established marker of astrocytes (Eng et al., 2000, Norazit et al., 2011), and ionized calcium binding adapter protein 1 (Iba-1), a microglial marker (Norazit et al., 2011, Ito et al., 1998), in combination with EdU labelling. 
Fig 5

a
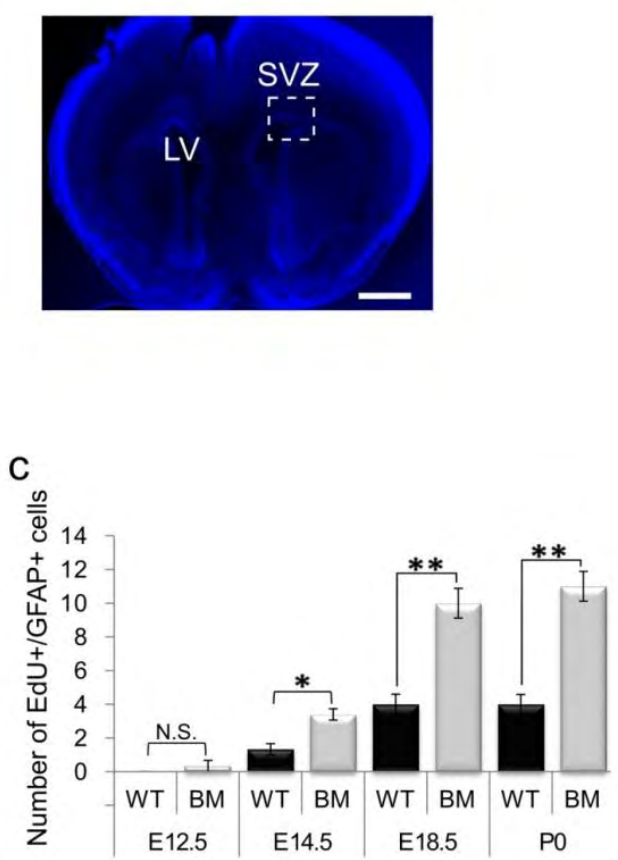

d

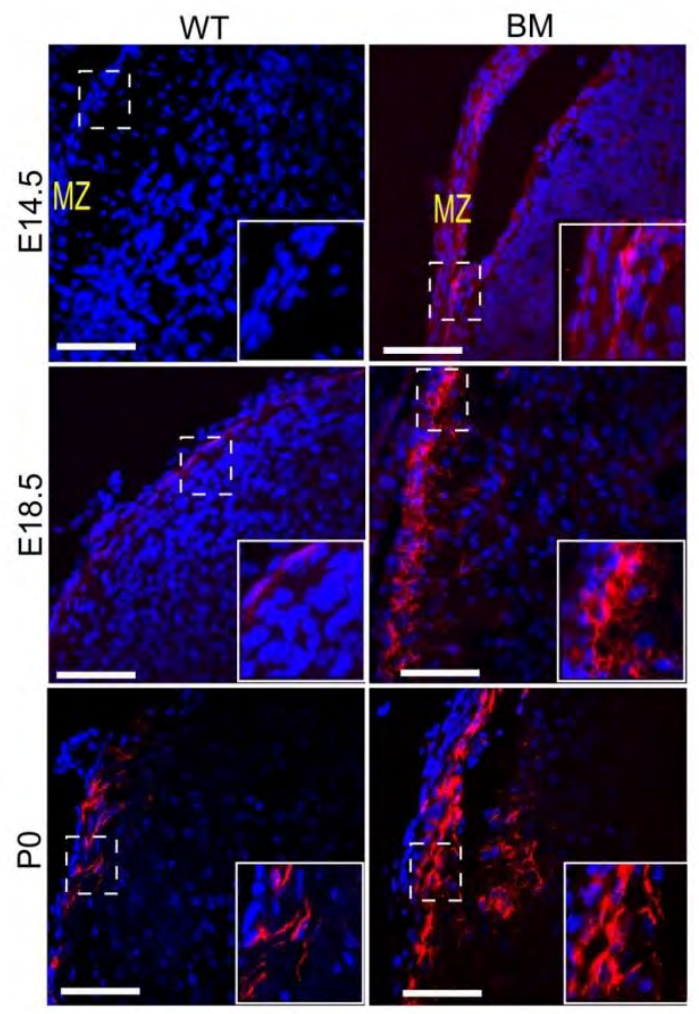

b

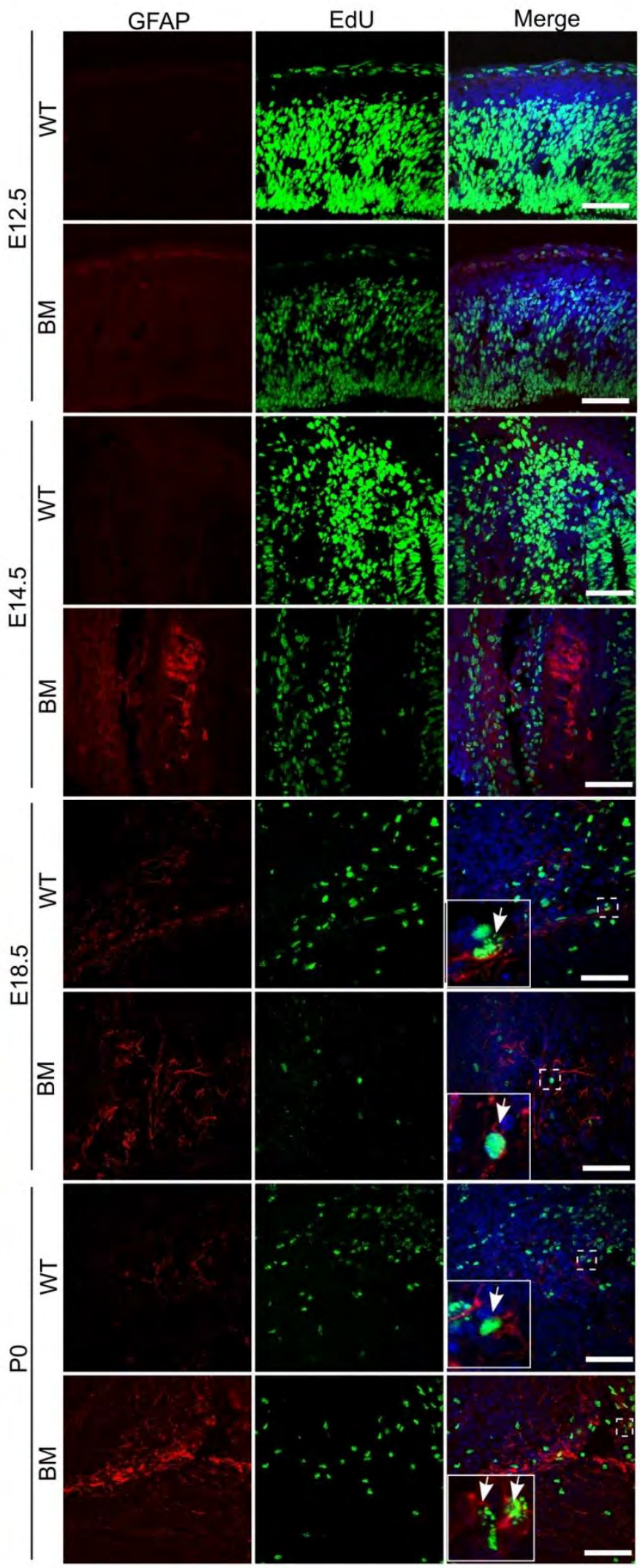


Fig. 5. PEX13 deficiency leads to astrocyte proliferation in the SVZ. (a) Coronal brain section with the white dotted box indicating the sampling region described in images b-d. (b) Representative images of astrogliosis (GFAP: red) showing immunoreactivity in the telencephalon area in coronal sections at multiple developmental stages. EdU, S-phase DNA (green); cell nuclei were stained with DAPI (blue). The dotted boxes in the bottom panels of $b$ are magnified, showing EdU labelled GFAP+ cells (white arrows). (c) The number of cells immunolabeled for both EdU and GFAP (EdU+/GFAP+) counted across a transect area of $1 \mathrm{~mm}^{2}$ in the SVZ area. (d) Representative images of GFAP+ cells (red) forming the periventricular region of the meninges (MZ). The dotted boxed areas are magnified in the lower right solid boxes of each panel. WT, wild-type; BM, PEX13 brain mutant; MZ, meninges. Scale bars $50 \mu \mathrm{m}$. Data represent mean \pm SEM ( $n=3$ animals for each group). ${ }^{*} p<0.05,{ }^{* *} p<0.01$, N.S., not significant.

Normally, gliogenesis arises late in embryogenesis (around the E17 stage) and persists beyond postnatal stages to adult brain, with low, ongoing generation of both astrocytes and oligodendrocytes (Rowitch and Kriegstein, 2010, Guerout et al., 2014, Molofsky and Deneen, 2015). At the E12.5 stage, the number of (GFAP+) astrocytes was low for both wild-type and PEX13 brain mutant mice (Fig. 5b, c). Astrocytes were first readily apparent in the wild-type mice at the E18.5 stage (Fig. 5b, c), but for the mutants were readily detectable by the E14.5 stage, and by E18.5 displayed thickened processes at the meninges (Fig. 5d). This higher GFAP staining persisted up to P0 for the mutants (Fig. 5b). We also calculated the number of cells that were positive for both GFAP and EdU (GFAP+/EdU+ cells): the mutants showed a significant increase in such cells from E18.5 through to P0 (Fig. 5b, c), consistent with increased proliferation of astrocytes at these later stages.

Findings similar to those for astroglia were observed for microglia. The mutants exhibited progressively higher numbers of cells with lba-1 immunofluorescence across all stages investigated, E12.5 to P0 (Fig. 6b, c, d). To assess microglia proliferation during these development stages, we counted the number of cells that were positive for both EdU and Iba-1 (EdU+/lba-1+ cells) in the SVZ. The results (Fig. 6c, e) indicated a significant increase in the number of these cells for the mutants, reaching a maximum 3-fold relative increase at P0. In situations of impaired neurogenesis or increased apoptosis, microglia migrate to and proliferate at the SVZ (Arno et al., 2014). We observed such an effect for the PEX13 brain mutants, with most microglia, especially at P0, found to be concentrated around the SVZ, but also at other sites (Fig. 6b). This increased localisation to the proliferating zone suggests a 
response to increased apoptosis. Together with the results above, this suggests there was decreased neuronal differentiation and increased glial proliferation. 
a

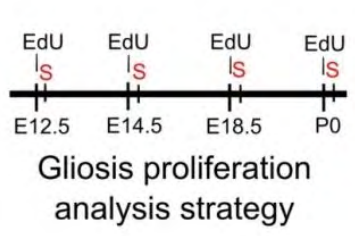

C
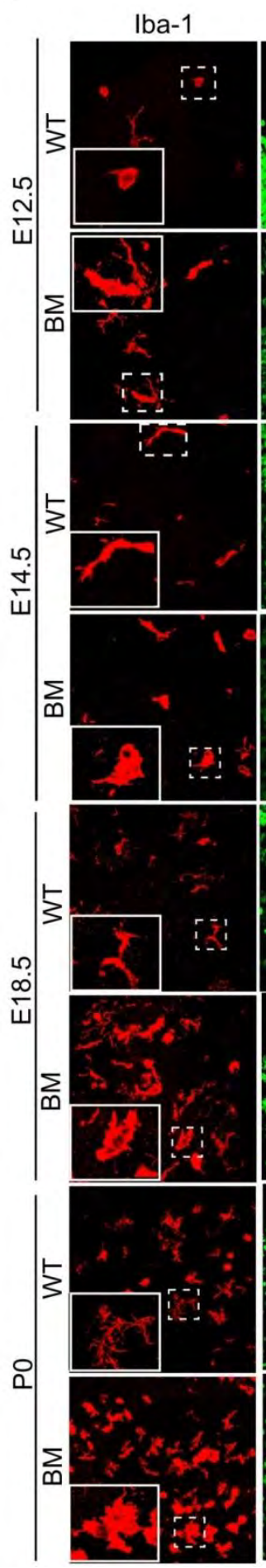

b
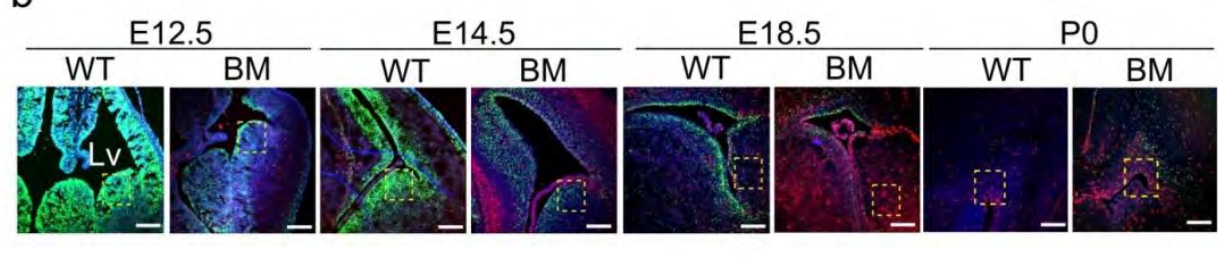

d

Fig 6

EdU Merge
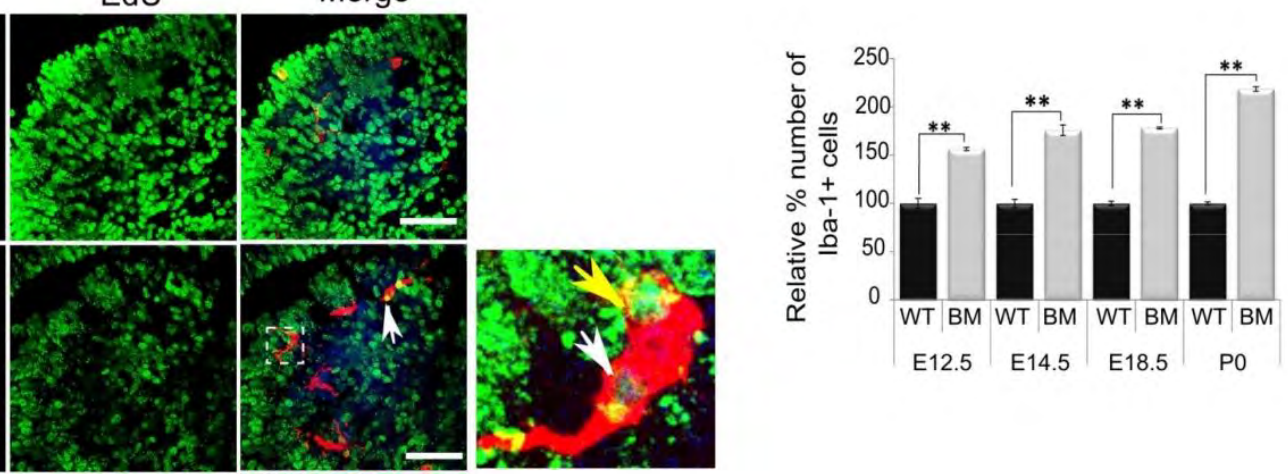

e
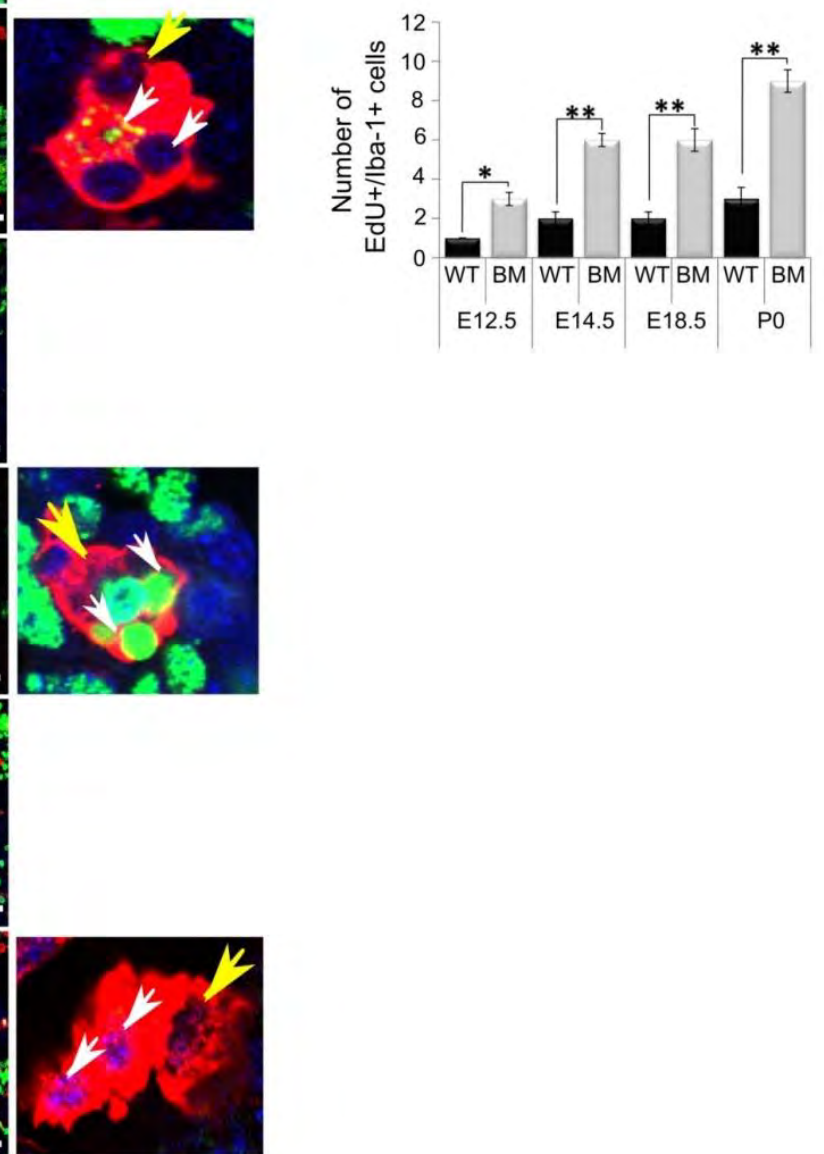
Fig. 6. PEX13 deletion leads to increased microglial proliferation and an increasing reactive gliosis with embryo maturation. (a) Experimental timeline for EdU-based analysis of gliogenesis, where an increasing microgliosis was demonstrated. (b) Low power images of wild-type and PEX13 brain mutants immunofluorescently labelled for EdU (green), anti-lba-1(red) and DAPI. Scale bars $200 \mu \mathrm{m}$. LV, lateral ventricle. (c) Higher magnification images of the white box areas shown in panel b of representative microglia demonstrating their phagocytic morphology. Selected lba-positive cells (white dotted boxes) are shown in magnification (solid white boxes). White arrowheads in the "Merge" images indicate EdUlabelled microglia. The far right panels for the BM images are magnified views of the dotted white boxes in "Merge" images, showing microglia phagocytosing apoptotic and EdU-positive cells. The white arrows indicate apoptotic cells nuclei which are either EdU labelled or unlabeled, the yellow arrows indicate microglial nuclei. Scale bars $50 \mu \mathrm{m}$. (d) The number of Iba-1+ cells expressed relative to that for wild-type mice. (e) The number of EdU+, Iba-1+ cells expressed relative to that for wild-type mice. WT, wild-type; BM, PEX13 brain mutant. Data represent mean \pm SEM ( $n=3$ animals for each group). ${ }^{*} p<0.05,{ }^{* *} p<0.01$.

Phagocytosis of apoptotic or neuronal debris is crucial to reduce inflammation and maintain healthy neuronal networks (Kettenmann et al., 2011), with microglia-mediated phagocytosis an established event in chronic inflammatory neurodegenerative disorders (Norazit et al., 2011, McArthur et al., 2010, Fuller and Van Eldik, 2008). Glial-mediated phagocytosis of apoptotic cells is assumed to be a highly important and effective process required to enable brain development (Magnus et al., 2001, Chan et al., 2001). For the PEX13 brain mutants, most microglia, from the E12.5 stage, showed a macrophage morphology (Norazit et al., 2011) which included enlarged cell bodies (Fig. 6c, left panel magnified views). These results are consistent with reactive microgliosis occurring during early embryonic brain development in the mutant and becoming more pronounced by postnatal stage $\mathrm{P} 0$, where more microglia exhibited an activated morphology and were interacting and phagocytosing neural progenitors and apoptotic cells (Fig. 6c, far right panel magnified view).

Given our observations of reactive gliosis in early developmental stages of PEX13 brain mutants, we looked for glial-mediated phagocytosis in these studies as a possible corrective mechanism for the abnormal neurodevelopmental processes occurring, and also because we observed large numbers of 
potentially apoptotic EdU labelled cells being phagocytosed by activated microglia (see supplementary Fig. S2). These analyses were consistent with increased rates of microglia-mediated phagocytosis.

Similar to what was seen for the SVZ, analysis of the dendate gyrus demonstrated higher numbers of activated (GFAP-positive) glia and (Iba-1-positive) microglia for the PEX13 brain mutants (Supplementary Fig. S3).

\section{Aberrant cell migration}

Cell migration is a vital process of neurodevelopment that follows cell differentiation. In the VZ, progenitors divide into intermediate progenitors and migrate towards the SVZ to establish a second zone where cells again divide, differentiate and migrate to further destinations (Marin and Rubenstein, 2003, Hatten, 1999). In early embryonic stages, intermediate progenitors, glia and projection neurons migrate radially from ventricular zones to the cortex wall (Parnavelas et al., 2000, Parnavelas, 2000, Parnavelas et al., 2002). The cortical interneurons produced at the ventral telencephalon (ganglionic eminence) migrate tangentially into the cerebral cortex layers (de Carlos et al., 1996, Marin and Rubenstein, 2003, Anderson et al., 1997). At postnatal stages, neuroblasts (which differentiate into interneurons) are generated at the dorso-lateral SVZ (dISVZ) and migrate tangentially to the olfactory bulb via the rostrocaudal stream (Luskin, 1993).

During postnatal stages, progenitors remain active in neurogenic areas such as the lateral ventricles and the dentate gyrus where they divide into new interneurons throughout adult life (Endaya et al., 2016, Alvarez-Buylla and Lim, 2004, Zhao et al., 2008). 
Fig 7

a

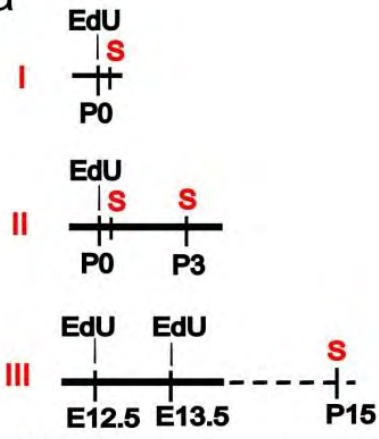

Migration analysis strategies b

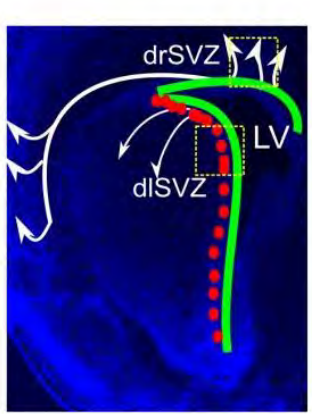

C

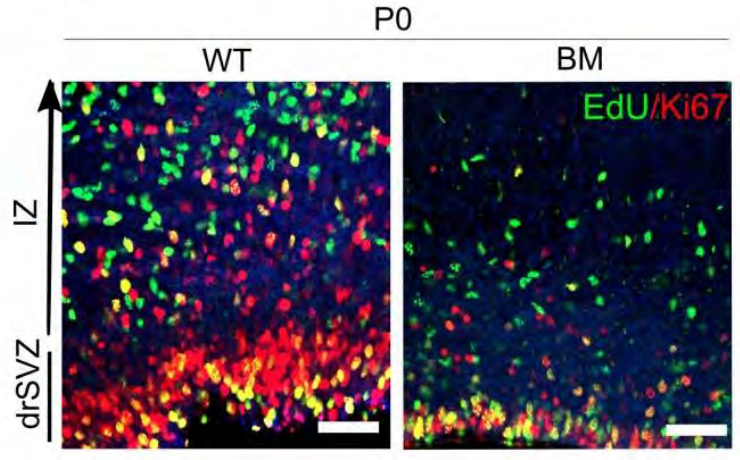

e

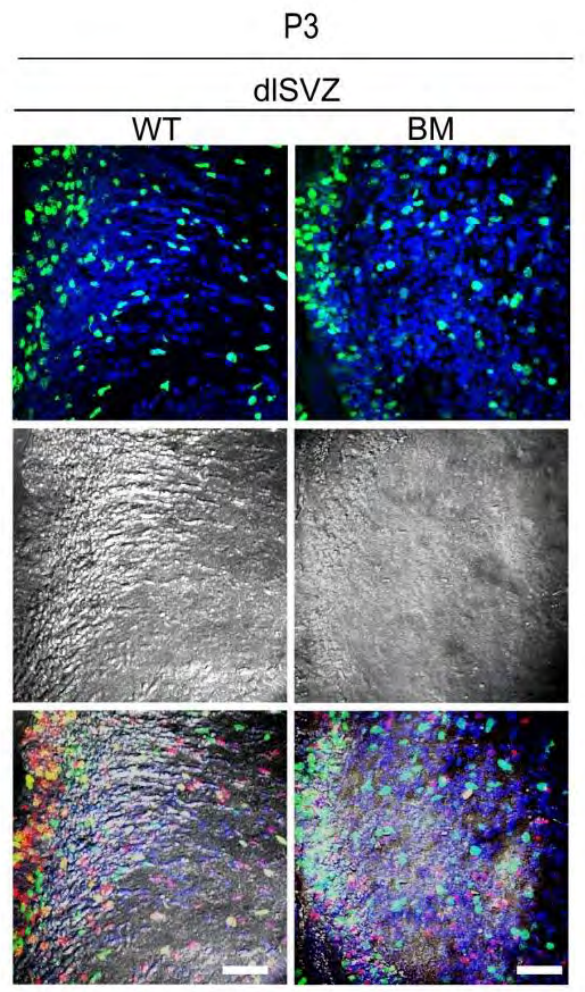

h

Relative \% number of EdU+ cells

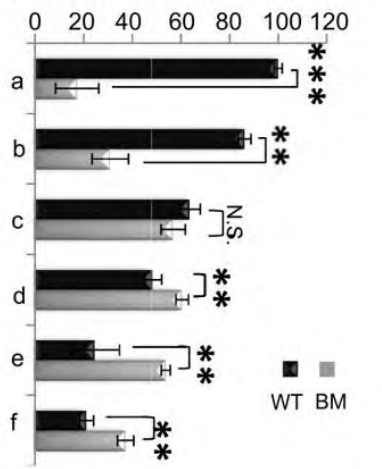


Fig. 7. PEX13 brain mutants show aberrant SVZ cell migration. (a) EdU labelling experimental strategy for migration analysis: BM dams were injected with EdU at P0 with 2 litters sacrificed at P0, (strategy I) and two harvested at P3 (strategy II). BM dams were injected at E12.5 and E13.5 (to maximize cell labelling) and the litters harvested at P15 (strategy III). (b) Image indicating migratory pathways of progenitors from the SVZ at postnatal stages P0-P3. White arrows indicate radial migration of projection neurons towards the cortex and glial cell migration to the cortex pallium surface and the striatum. Red dots indicate tangential migration (perpendicular to the plane) of neuronal progenitors from the dorso-lateral SVZ (shown by the green line) and towards the olfactory bulb through the RMS pathway. The sampling regions included the dorso-lateral SVZ (dISVZ) and dorsal roof of the SVZ (drSVZ) (dotted boxes). LV, lateral ventricle. (c) Higher magnification views of stem and neuronal progenitor proliferation in the SVZ region in the PO brain; black arrow indicates the direction of progenitor migration. The sections were labelled with EdU (green), Ki67 (red), and DAPI (blue). In the PEX13 brain mutant, a marked lack of Ki67 labelled cells was noted in the IZ regions, with the majority being located in the SVZ (P0 stage). (d) At P3, similar areas (drSVZ and dISVZ) were observed for cell migration. EdU labelled cells had migrated from the SVZ into the IZ region in the WT brain, whereas few EdU labelled cells had been produced and migrated out of the SVZ in the PEX13 BM mice. Immunofluorescence and DIC microscopy revealed significant reductions in two types of spherical cells (i.e. proliferating glia and post mitotic migrating neurons) in the SVZ of the mutant mice. (e) Neuronal progenitor proliferation and migration at dorsal lateral SVZ. (f) The relative number of EdU+ cells at SVZ and IZ was significantly lower for PEX13 brain mutants. (g) Reduced cortical cell/progenitor migration in the mutants with proliferating cells labelled at E12.5 and E13.5 and quantified at P15. For this analysis, arbitrary-sized consecutive regions (a-f) were selected for cell counting. The black arrow (at right) indicates the direction of normal neuronal migration. (h) The proportion of EdU+ labelled cells for the selected regions a-f indicates migration towards the cortical plate which is markedly reduced in the BM mice. Scale bars, $50 \mu \mathrm{m}$. BM, PEX13 brain mutant; WT, wild-type. Data represent mean \pm SEM ( $n=3$ animals for each group). ${ }^{*} p<0.05,{ }^{* *} p<0.01,{ }^{* * *} p<0.001$, N.S., not significant.

Given the results reported above of modified proliferating cells distribution at the P0 stage, we investigated the process of migration using EdU-based experiments of coronal brain sections in two groups of animals: (1) P0 pups injected with EdU (50 mg/kg i.p.) and sacrificed $4 \mathrm{~h}$ later (designated P0 stage), and (2) P0 pups injected on the day of birth and sacrificed 3 days later (designated P3 stage) (Fig. 7a). To calculate the number of cells (intermediate progenitors and glia) migrating from the dorsal roof of 
the SVZ (drSVZ) towards the cortex, the sampling region was selected from drSVZ to IZ and for the analyses of other group of cells (neuroblasts), the dorso-lateral SVZ (dISVZ) region was selected during P0 to P3 stages.

In comparison to wild-type mice, the mutants showed reduced numbers of EdU+-cells, especially at the IZ (panel c) at the P0 stage (Fig. 7c). Similar findings were obtained at the P3 stage (Fig 7d). Using DIC microscopy, we also demonstrated a significant reduction in cell density across the entire SVZ/IZ region for the mutants (Fig. 7d). Wild-type mice had a large number of EdU+ cells in both the drSVZ and IZ (Fig. 7d, f), consistent with active cell genesis in the dISVZ (Fig. 7e, f) and subsequent migration to their final location through radial or tangential migration. In contrast, EdU analysis showed that the mutants had far fewer EdU+ cells in the drSVZ, and even less in the IZ. Similarly, there was a significant reduction in the number of EdU+ cells at the dISVZ. Analysis of the ratio of cells in the IZ compared to the SVZ indicates a much lower ratio for the mutants, which may suggest decreased migration of EdU+ cells from the SVZ to IZ during the P0-P3 interval.

During early postnatal stages, division of radial glial cells declines and the population of intermediate progenitors is reduced to nominal numbers, such that only radial glial daughter cells are present at the SVZ, with these being converted to glia and ependymal cells (Götz and Huttner 2005). Given this, the number of EdU+ cells at the drSVZ region seen here may be inferred to represent predominantly proliferating glia and a few projection neurons (which contribute to developing the cerebral cortex superficial layer). On the other hand, the number of EdU+ cells at the dISVZ comprise a population of neuroblasts, which further migrate tangentially towards the olfactory bulb and differentiate into interneurons (Wichterle et al., 1997). Thus the above data may suggest reduced cell proliferation and migration from the drSVZ to the cortex in PEX13 brain mutants, and reduced generation of neuroblasts at the dISVZ, indicating decreased overall neuronal progenitor proliferation.

We also investigated the process of migration of cortical neurons towards the cortical plate. For this analysis, two pregnant dams were injected with EdU on two consecutive days (E12.5 and E13.5 stages), and harvested at the P15 stage to assess neuronal survival and integration. The region 
encompassing the cortex was divided into 6 similar width layers (designated a-f) (Fig. $7 \mathrm{~g}$ ) and the number of cells in each layer counted to provide an estimation of the cell profile across this entire region.

Compared to wild-type mice, where EdU+ cells were concentrated towards the upper field of the cortical region, EdU+ cells in the mutants were distributed more within the deep layers of the cortex (Fig. $7 \mathrm{~g}, \mathrm{~h})$, consistent with a migration defect in these cells. Our finding is consistent with our previous report of abnormal lamination of the cerebral cortex in PEX13-null mice, and potentially provides a mechanism for the observed cell distribution pattern (high densities around the ventricles) in ZS patients (Nakai et al., 1995).

\section{Aberrant developmental sequences: defective serotonergic specification and integration}

We recently reported on significant reduction in tph2 gene expression and changes to the serotonergic system in postnatal PEX13 brain mutant mice (Rahim et al., 2014). Tph2 is the rate limiting enzyme of serotonin (5-hydroxytryptamine, or 5-HT) biosynthesis and extensive data supports morphogenic effects of 5-HT on proliferation, differentiation, resettlement, and endurance of cells (Gaspar et al., 2003). 5-HT appears earlier than maturation of raphe serotonergic neurons, signifying a fundamental role in embryonic brain development as well as the specific development and maturation of the serotonergic system per se.

To evaluate serotonergic neurogenesis and cell specification at relevant postnatal stages, we used three experimental approaches, noting that the ventralisation and lineage commitment (specification) to the two midbrain nuclei, the raphe nucleus and the substantia nigra/ventral tegmental area, occur at the ventral mesencephalon immediately rostral to the isthmic organizer (isthmus), and occurs at E11-E13 in the mouse embryo.

In the first approach, serotonergic cell genesis was assessed by short term EdU injection at the E12.5 stage, with tissues harvested after $4 \mathrm{~h}$ to assess the dividing cell population that gives rise to serotonergic neurons. In the second approach, embryos labelled with EdU at E9.5 and E10.5, to label all 
rostral and most of the caudal ( $r 1-r 8)$ serotonergic cells (in mice, progenitors give rise to serotonergic neurons in the ventral rhombo-cephalon between E9.5-E11.5 stage (Deneris and Wyler, 2012) were harvested, following specification, at P0. In the third experimental approach, EdU was injected on two consecutive days (E12.5 and E13.5 stages) and harvested at the P15 stage (to assess the "adult" phenotype). Tissues were assessed with EdU-labeling, in combination with NeuN (a marker of mature neurons), and TPH2 (serotonergic neurons), to quantify serotonergic specification in the normal and PEX13 genotypes. 
a
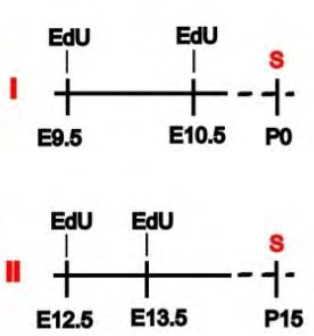

Serotonergic developmental analysis strategies

b(iii)

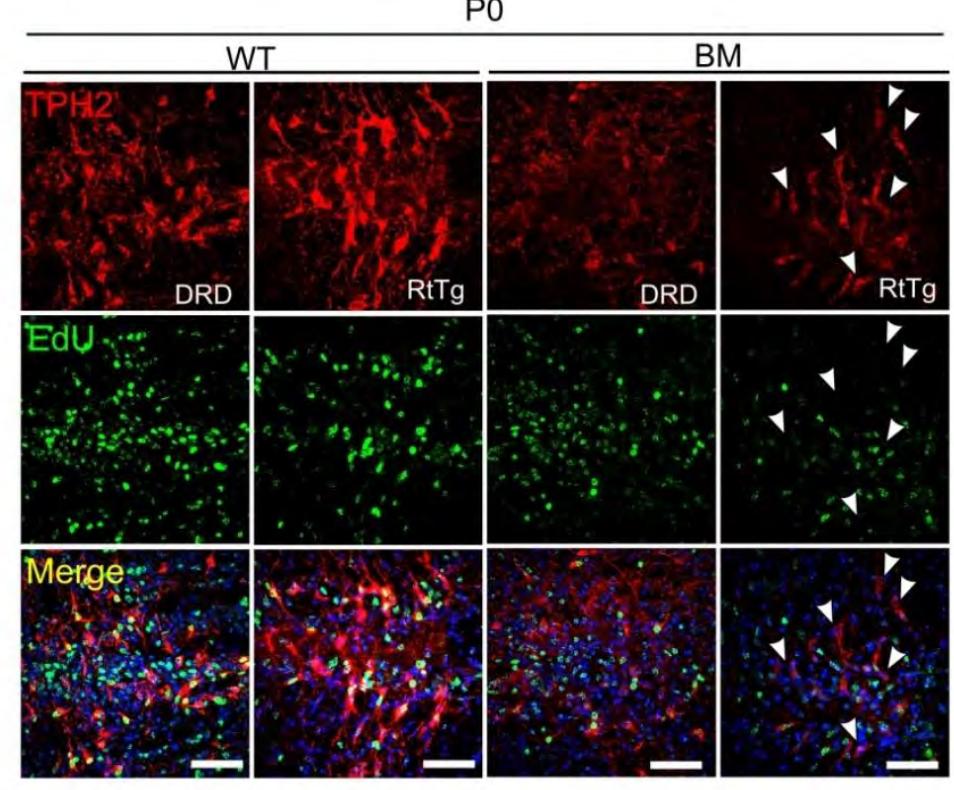

e

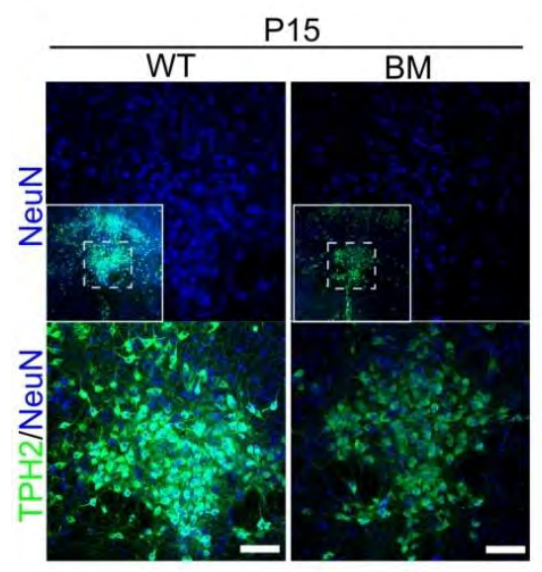

b(i)

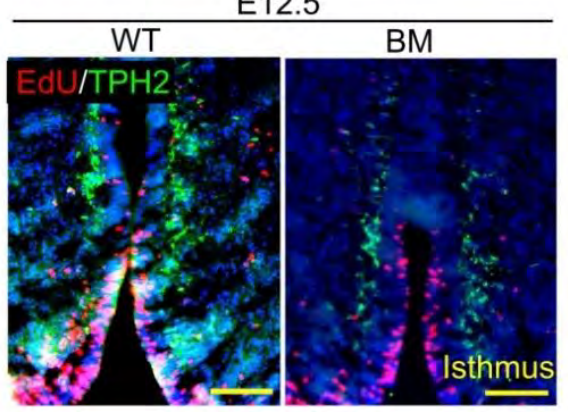

f

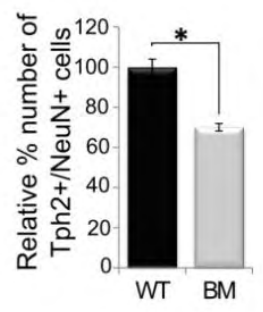

b(ii)

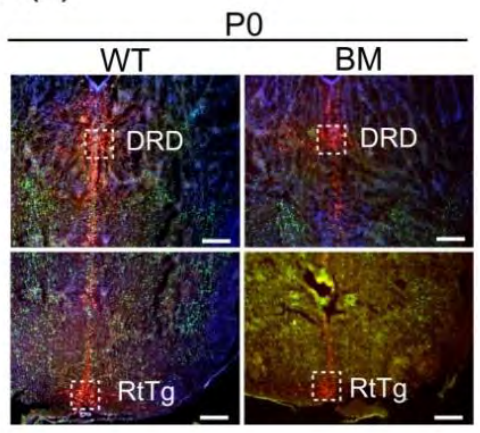

C

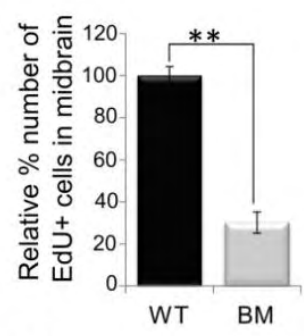

d

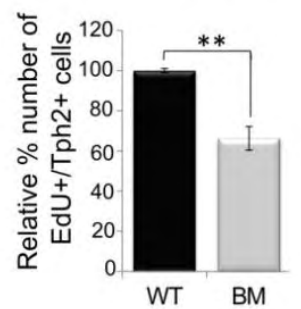


Fig. 8. PEX13 deficiency affects the early development of the serotonergic system (raphe nucleus). (a) To establish cell fate of ventral progenitors of serotonergic neurons in the isthmus region, dams were injected with EdU at E9.5 plus E10.5 and the brains harvested for analysis at birth (P0) (strategy I) or injected at E12.5 plus E13.5 and the brains harvested for analysis at 15 days post-partum (P15) (strategy II). The pups were sacrificed (S) and immuno-labelled for TPH2, a marker of differentiated serotonergic neurons. b (i) The neurogenic region of the isthmus, which gives rise to monoaminergic neurons, including the serotonergic neurons of the raphe nucleus, were identified at E12.5 using a pulse of EdU prior to tissue harvest and subsequent EdU (red) labelling and immune-labelling for TPH2 (green). Scale bar, $200 \mu \mathrm{m}$. (b) (ii) Low power images of the serotonergic cell population in the isthmus at the P0 stage, with the dorsal raphe nucleus (DRD) and reticular tegmental nucleus of the pons (RtTg) regions demarcated by the white rectangles. Scale bar, $500 \mu \mathrm{m}$. b (iii) magnified to show co-localization of EdU and Tph2 within the same neurons. White arrowheads indicate EdU-/Tph2+ cells in the RtTg area of mutant brain. (c) The number of EdU+ cells expressed relative to numbers for wild-type animals in midbrain at P0 stage. (d) The number of EdU+/TPH2+ cells in the dorsal raphe nucleus in the midbrain at P0. Scale bar, $100 \mu \mathrm{m}$. (e) To establish serotonergic cell specification, coronal sections were immunolabelled at P15 with anti-TPH2 (green) and NeuN antibody to detect mature neurons (blue). Scale bar, $100 \mu \mathrm{m}$. (f) The number of $\mathrm{TPH} 2+/ \mathrm{NeuN}+$ cells expressed relative to numbers for wild-type mice in the midbrain at the P15 stage.

On harvesting of tissues following EdU injection at the E12.5 stage (4 h post EdU injection), neither wild-type nor mutant mice showed Tph2-immunolabelled cells that were also labelled with EdU (Fig. 8 b(i)), consistent with cessation of serotonergic cell genesis by E12.5 (Deneris and Wyler, 2012). A reduced number of serotonergic neurons was seen in the mutants in the isthmus region (Fig. $8 \mathrm{~b}(\mathrm{i})$ ), as well as a reduced number of EdU+ cells, indicating an overall reduction in cell genesis at the isthmus region.

To analyse serotonergic cell specification, progenitor cells of serotonergic neurons in the ventral rhombo-cephalon were EdU-labelled by EdU injection on two consecutive days, E9.5 and E10.5, and tissue harvested from the isthmus region and analyzed at P0. Coronal sections were fluorescently labelled with EdU and anti-Tph2 immunofluorescence was used to identify serotonergic cells. The number of EdU+ cells was reduced 3-fold in the mutant mid-brains compared to the wild-type brains (Fig. 8 b(ii, iii), c), indicating reduced overall cell genesis in the mutants. For the wild-type animals, all Tph2+ cells in the isthmus region were also EdU+ (Fig. 8 b(ii, iii), d), consistent with all serotonergic neurons generated 
by progenitor cells at the E9.5-E10.5 stages migrating to their location in the isthmus. In contrast, the mutants showed the expected reduction in the number of Tph2+ cells, but also a reduction in the number of Tph2+/EdU+ cells (Fig. 8 b(ii,iii), d). These reduced Tph2 cell numbers were also reflected in the total cell numbers detected using DAPI staining (Fig 8 b(ii, iii)).

To assess serotonergic cell specification, we also measured the number of Tph2+ cells that were also immunolabeled for NeuN, a marker of mature neurons (Sarnat et al., 1998). The mutants had approximately $30 \%$ less $\mathrm{Tph} 2+/ \mathrm{NeuN}+$ cells than wild-type mice (Fig. 8e, f), consistent with reduced specification and survival of mature serotonergic neurons, and consistent with our previous report of reduced serotonergic cell numbers in the PEX13 mutant brain (Rahim et al., 2014).

\section{Increased cell death}

To determine if apoptosis is associated with these changes, we also immune-labelled the isthmus region with an antibody to cleaved caspase-3, a validated marker of cells undergoing programmed cell death (Nicholson et al., 1995).

a

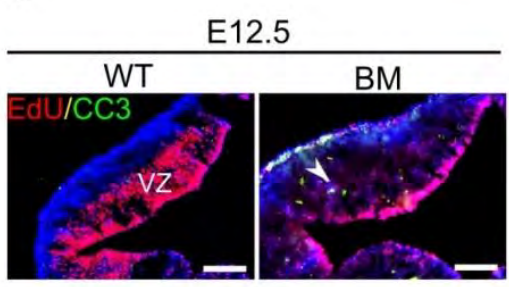

C

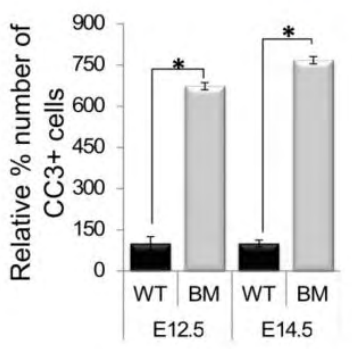

E14.5

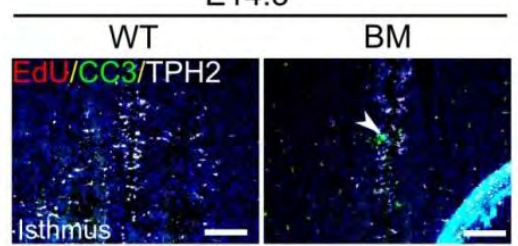

isthimis b

BM E14.5
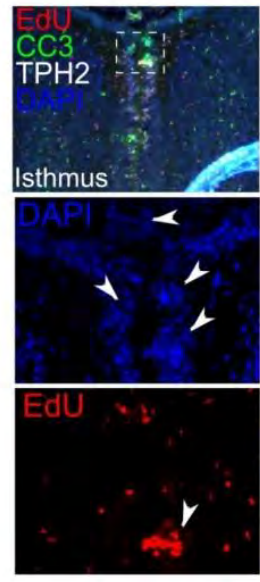
Fig. 9. PEX13 deficiency leads to increased cell death in the VZ and in the developing serotonergic system (raphe nucleus). (a) Representative image showing cleaved caspase 3 (CC3)-immunolabelled cells in the VZ and isthmus region of midbrain at E12.5 to E14.5. White arrows indicate clusters of apoptotic cells. Scale bars, $200 \mu \mathrm{m}$. (b) The area of the isthmus region of E14.5 stage PEX13 brain mutant brain, demarcated by the white box in the top left panel, is magnified in the remaining individual panels (CC3, TPH2, DAPI, EdU) to highlight (white arrowheads) a cluster of apoptotic cells (CC3-positive; pyknotic nuclei), many of which are TPH2-positive, EdU-positive, or both TPH2/EdU-positive. (c) The number of cells immunoreactive for $\mathrm{CC} 3+$ at E12.5 and E14.5 in the midbrain. Data represent mean \pm SEM $(n=3) ;{ }^{*} p<0.05,{ }^{* *} p<0.01, W T$, wild-type, BM, PEX13 brain mutant, SVZ, subventricular zone.

For wild-type mice at the E12.5 and E14.5 stages there were very few apoptotic cells detected, whereas we observed an approximate 7-fold relative increase in the number of $\mathrm{CC} 3+$ cells for the mutants, with a high proportion of CC3+ cells also EdU labelled (Fig. 9a, b, c). At the E14.5 stage of mutants, and specifically in the isthmus region, we detected a significant increase in the number of CC3+ cells clustered in the vicinity of the Tph2+ cell population (Fig. 9a, b). These results are consistent with apoptosis concomitant with abnormal neurogenesis in the mutants.

\section{Discussion}

These investigations on PEX13 brain mutant mice have provided a number of findings that indicate significant neurodevelopmental abnormalities that may underpin the molecular neuropathology of these animals and by inference the processes occurring in ZS.

Firstly, we demonstrate gross morphological anomalies that first appear at early embryonic stages. The most pronounced changes were enlargement of the most frontal aspects of the cortex, smaller olfactory bulbs, and enlarged and dilated lateral ventricles, all of which persisted after birth. Importantly, similar morphological defects have been observed for neonatal ZS patients (Nakai et al., 
1995), suggesting that the PEX13 brain mutants are modelling changes seen for ZS patients. We also observed cortical disorganization, including irregular thicknesses along the mediolateral axis of the neocortex, which suggests defective organisation of the anterior telencephalon area. We previously reported on abnormal cortical lamination for PEX13 null mice (Maxwell et al., 2003), and similar cytoarchitectural defects in the cerebellum and cerebral cortex have been observed for PEX2-null mice (Faust et al., 2005). Our previous findings suggested that there were no gross phenotypic differences between mutant and control mice when the mass of the brain was measured at P0 (Muller et al, 2011). This current work however, demonstrate that the brains of mutant mice at P0 are smaller when measured along the longitudinal axis, than the brains of control mice. This inconsistency may be attributed to the difference in technique for measuring the brain. Secondly, we established that PEX13 deficiency results in a modulatory effect on the proliferation of progenitors at the SVZ and DG neurogenic zones, and concomitant reduction in the number of differentiated neurons - these changes were specifically exemplified by the loss of differentiation of serotonergic neurons. These findings are potentially due to a decline in the population of progenitor cells in these neurogenic pools, defects in cell division or differentiation, or increased, premature proliferation of glia.

Thirdly, the PEX13 brain mutants display a defect in the migration of differentiating neurons to the cerebral cortex, consistent with previous studies of PEX knockout mice (Baes et al., 1997, Faust, 2003, Faust and Hatten, 1997, Maxwell et al., 2003).

Fourthly, we demonstrate that PEX13 deficiency results in increased reactive gliosis that commences during early embryonic stages and persists postnatally.

\section{Defective proliferation, differentiation, and migration}

Our findings suggest that PEX13 deficiency during embryonic development causes reduced progenitor proliferation and differentiation into mature neurons and the migration of intermediate progenitors from the VZ to their expected locations in the SVZ/IZ zone. We observed that most progenitor cells remained in the S-phase cycle at VZ, with few cells generating intermediate progenitors that migrated from the VZ to the SVZ. Given that the SVZ/IZ represent zones from which post-mitotic neurons 
migrate radially to the cortex, these findings correlate with previous reports of migration defects in the granule cell layer and abnormal Purkinje cell differentiation in cerebellum (Muller et al., 2011, Faust, 2003) and abnormal lamination of the cerebral cortex in PEX2, PEX5 and PEX13 mutants (Faust and Hatten, 1997, Faust, 2003, Krysko et al., 2007, Maxwell et al., 2003). Delayed neuronal migration has been observed in patients across the ZS spectrum as well as for patients with D-bifunctional protein deficiency, who have a similar phenotype to ZS patients (Powers et al., 1985).

Given our recent report of significant abnormalities with the serotonergic system in PEX13 brain mutants (Rahim et al., 2014), we also investigated this specific system in the context of the general changes to neurogenesis and cell migration. The results demonstrate that PEX13 deficiency also affects early development of the serotonergic system. We observed reduced genesis and delayed migration of serotonergic cells and a concomitant increase in the number of apoptotic serotonergic cells in the vicinity of the midline of the isthmus area of mutants, which we again interpret as suggesting accelerated rates of apoptosis as a result of delayed migration and improper positioning. Serotonin (5-HT) is considered an important regulator of morphogenetic activities during early CNS development as 5-HT neurons are among the first neurons to emerge and 5-HT plays major roles in more global cell proliferation, migration, and differentiation (Lauder and Bloom, 1975, Gould, 1999, Buznikov et al., 2001). In mice, brain serotonin deficiency affects the postnatal development of neuronal circuitry (Migliarini et al., 2013), and even minor fluctuations in 5-HT synthesis and distribution in the brain are closely linked to variations in neurogenesis and proliferation at neurogenic areas in adult rat brain (Brezun and Daszuta, 1999, Azmitia, 2001). Thus it is possible that the serotonin deficiency seen in the PEX13 brain mutants exacerbates the neurodevelopmental defects.

\section{The potential impacts of gliosis}

In ZS patients, pronounced neuroinflammation has not yet been reported, however demyelinating lesions of immature white matter with mild astrogliosis and sudanophilic macrophages have been observed (Wisniewski et al., 1989). In addition, abnormal pleomorphic cytosomes with variable lipid content have 
been detected in astrocytes, oligodendrocytes, immature neurons, neuroblasts and radial glia of ZS abortuses (Powers et al., 1989, Wisniewski et al., 1989).

In contrast, PEX5-null mice (Bottelbergs et al., 2010) and mice with brain restricted PEX5 and PEX13 deletion (Muller et al., 2011, Rahim et al., 2014, Hulshagen et al., 2008) exhibit pronounced neuroinflammation. The involvement of pronounced astrogliosis has been observed in a diverse range of neurodevelopmental disorders (Ge et al., 2012, Stipursky and Gomes, 2007) and linked with altered growth of neuronal populations during neurodevelopment (Ge et al., 2012). The findings for the PEX13 brain mutants of increased reactive gliosis at early neurodevelopmental stages may presage an adverse effect on neurogenesis and constrain differentiation of progenitors into neurons in later neurodevelopmental stages, as has been shown in other conditions (Wilhelmsson et al., 2012).

Microglia play important roles in modulating neurodevelopmental events such astro-genitor viability, cell proliferation, differentiation and migration (Sierra et al., 2010). Unlike astroglia, microglia do not differentiate from progenitors. Instead, they are generated from the yolk sac at the E8-E10 stage (McGrath et al., 2003) and accumulate in meninges and forebrain prior to neurogenesis, before invading the cortical wall and migrating towards the VZ/SVZ area of the developing cortex into which they seed and proliferate (Alliot et al., 1999, Rezaie and Male, 1999). Compared to wild-type animals, PEX13 brain mutants had increased number of activated microglia (macrophage) around the proliferating zone and marginal zone/meninges, which suggests increased microglial proliferation and activation in neurogenic areas. As microglia are known to be activated under two conditions - when there is a reduction of neurogenesis or dysfunction of the neurotrophic system (Kobayashi et al., 2013, Liao et al., 2012), and when protection of neurons is required (Beschorner et al., 2007) - these findings are consistent with pronounced disturbance of neurogenic pathways for the mutants.

Microglial phagocytosis of apoptotic or degenerated neuronal debris is crucial to reduce inflammation and maintain healthy neuronal networks in brain microenvironments (Block et al., 2007).

For PEX13 brain mutants, these rates of apoptosis and microglial phagocytosis were significantly higher than normal, indicating involvement of microglia in early neurodevelopmental cellular death and 
neuroinflammation. In this regard, findings from mice with brain PEX5 deficiency have demonstrated that neuroinflammation appears before axonal degeneration (Bottelbergs et al., 2012), which suggests a primary involvement of neuroinflammation in the neuropathology of these animals

Overall, the findings from these investigations suggest that PEX13 deficiency in brain leads to aberrant neurodevelopmental changes, and associated gliosis during early central nervous development. These abnormalities provide a potential explanation of the neurodevelopmental deficits and gross brain dysmorphology observed for brains of postnatal PEX13 brain mutants.

\section{Ethical Approval:}

All applicable international, national and institutional guidelines for the care and use of animals were followed. All procedures performed in studies involving animals were in accordance with the ethical standards of Griffith University (BBS/02/09/AEC; ESK/03/13/AEC).

\section{REFERENCES}

ALLIOT, F., GODIN, I. \& PESSAC, B. 1999. Microglia derive from progenitors, originating from the yolk sac, and which proliferate in the brain. Brain Res Dev Brain Res, 117, 145-52.

ALTMAN, J. 1963. Autoradiographic investigation of cell proliferation in the brains of rats and cats. Anat Rec, 145, 573-91. 
ALTMAN, J. 1969. Autoradiographic and histological studies of postnatal neurogenesis. IV. Cell proliferation and migration in the anterior forebrain, with special reference to persisting neurogenesis in the olfactory bulb. J Comp Neurol, 137, 433-57.

ALTMAN, J. \& BAYER, S. A. 1990. Migration and distribution of two populations of hippocampal granule cell precursors during the perinatal and postnatal periods. J Comp Neurol, 301, 365-81.

ALVAREZ-BUYLLA, A. \& LIM, D. A. 2004. For the long run: maintaining germinal niches in the adult brain. Neuron, 41, 683-6.

ANDERSON, S. A., EISENSTAT, D. D., SHI, L. \& RUBENSTEIN, J. L. 1997. Interneuron migration from basal forebrain to neocortex: dependence on Dlx genes. Science, 278, 474-6.

ARNO, B., GRASSIVARO, F., ROSSI, C., BERGAMASCHI, A., CASTIGLIONI, V., FURLAN, R., GRETER, M., FAVARO, R., COMI, G., BECHER, B., MARTINO, G. \& MUZIO, L. 2014. Neural progenitor cells orchestrate microglia migration and positioning into the developing cortex. Nat Commun, 5, 5611.

ARNOLD, G. \& HOLTZMAN, E. 1978. Microperoxisomes in the central nervous system of the postnatal rat. Brain Res, 155, 1-17.

AZMITIA, E. C. 2001. Modern views on an ancient chemical: serotonin effects on cell proliferation, maturation, and apoptosis. Brain Res Bull, 56, 413-24.

BAES, M., GReSSENS, P., BAUMgart, E., CARMELIET, P., CASTEELS, M., FRANSEN, M., EVRARD, P., FAHIMI, D., DECLERCQ, P. E., COLLEN, D., VAN VELDHOVEN, P. P. \& MANNAERTS, G. P. 1997. A mouse model for Zellweger syndrome. Nat Genet, 17, 49-57.

BAYER, S. A., ALTMAN, J., DAl, X. F. \& HUMPHREYS, L. 1991. Planar differences in nuclear area and orientation in the subventricular and intermediate zones of the rat embryonic neocortex. $J$ Comp Neurol, 307, 487-98.

BESCHORNER, R., SIMON, P., SCHAUER, N., MITTELBRONN, M., SCHLUESENER, H. J., TRAUTMANN, K., DIETZ, K. \& MEYERMANN, R. 2007. Reactive astrocytes and activated microglial cells express EAAT1, but not EAAT2, reflecting a neuroprotective potential following ischaemia. Histopathology, 50, 897-910.

BLOCK, M. L., ZECCA, L. \& HONG, J. S. 2007. Microglia-mediated neurotoxicity: uncovering the molecular mechanisms. Nat Rev Neurosci, 8, 57-69.

BOtTelbergs, A., VerheiJden, S., HUlShagen, L., GUtMANN, D. H., GOEBBelS, S., NAVE, K. A., KASSMANN, C. \& BAES, M. 2010. Axonal integrity in the absence of functional peroxisomes from projection neurons and astrocytes. Glia, 58, 1532-43. 
BOtTelbergs, A., Verheijden, S., VAN VELDhOVEN, P. P., JUST, W., DEVOS, R. \& BAES, M. 2012. Peroxisome deficiency but not the defect in ether lipid synthesis causes activation of the innate immune system and axonal loss in the central nervous system. J Neuroinflammation, 9, 61.

BRAVERMAN, N. E. \& MOSER, A. B. 2012. Functions of plasmalogen lipids in health and disease. Biochim Biophys Acta, 1822, 1442-52.

BRAZELTON, T. R., ROSSI, F. M., KESHET, G. I. \& BLAU, H. M. 2000. From marrow to brain: expression of neuronal phenotypes in adult mice. Science, 290, 1775-9.

BREZUN, J. M. \& DASZUTA, A. 1999. Depletion in serotonin decreases neurogenesis in the dentate gyrus and the subventricular zone of adult rats. Neuroscience, 89, 999-1002.

BRITES, P., WATERHAM, H. R. \& WANDERS, R. J. 2004. Functions and biosynthesis of plasmalogens in health and disease. Biochim Biophys Acta, 1636, 219-31.

BUZNIKOV, G. A., LAMBERT, H. W. \& LAUDER, J. M. 2001. Serotonin and serotonin-like substances as regulators of early embryogenesis and morphogenesis. Cell Tissue Res, 305, 177-86.

CHAN, A., MAGNUS, T. \& GOLD, R. 2001. Phagocytosis of apoptotic inflammatory cells by microglia and modulation by different cytokines: mechanism for removal of apoptotic cells in the inflamed nervous system. Glia, 33, 87-95.

CHAPKIN, R. S., KIM, W., LUPTON, J. R. \& MCMURRAY, D. N. 2009. Dietary docosahexaenoic and eicosapentaenoic acid: emerging mediators of inflammation. Prostaglandins Leukot Essent Fatty Acids, 81, 187-91.

CHEHREHASA, F., MEEDENIYA, A. C., DWYER, P., ABRAHAMSEN, G. \& MACKAY-SIM, A. 2009. EdU, a new thymidine analogue for labelling proliferating cells in the nervous system. J Neurosci Methods, $177,122-30$.

DE CARLOS, J. A., LOPEZ-MASCARAQUE, L. \& VALVERDE, F. 1996. Dynamics of cell migration from the lateral ganglionic eminence in the rat. $J$ Neurosci, 16, 6146-56.

DENERIS, E. S. \& WYLER, S. C. 2012. Serotonergic transcriptional networks and potential importance to mental health. Nat Neurosci, 15, 519-27.

DIRKX, R., VANHOREBEEK, I., MARTENS, K., SCHAD, A., GRABENBAUER, M., FAHIMI, D., DECLERCQ, P., VAN VELDHOVEN, P. P. \& BAES, M. 2005. Absence of peroxisomes in mouse hepatocytes causes mitochondrial and ER abnormalities. Hepatology, 41, 868-78.

DOETSCH, F. \& ALVAREZ-BUYLLA, A. 1996. Network of tangential pathways for neuronal migration in adult mammalian brain. Proc Natl Acad Sci U S A, 93, 14895-900. 
ENdAyA, B., CAVANAGH, B., ALOWAidI, F., WALKeR, T., DE PENNINGTON, N., NG, J. M., LAM, P. Y., MACKAY-SIM, A., NEUZIL, J. \& MEEDENIYA, A. C. 2016. Isolating dividing neural and brain tumour cells for gene expression profiling. J Neurosci Methods, 257, 121-33.

ENG, L. F., GHIRNIKAR, R. S. \& LEE, Y. L. 2000. Glial fibrillary acidic protein: GFAP-thirty-one years (19692000). Neurochem Res, 25, 1439-51.

FAROOQUI, A. A. 2012. n-3 fatty acid-derived lipid mediators in the brain: new weapons against oxidative stress and inflammation. Curr Med Chem, 19, 532-43.

FAROOQUI, A. A., HORROCKS, L. A. \& FAROOQUI, T. 2007. Modulation of inflammation in brain: a matter of fat. J Neurochem, 101, 577-99.

FAUST, P. L. 2003. Abnormal cerebellar histogenesis in PEX2 Zellweger mice reflects multiple neuronal defects induced by peroxisome deficiency. J Comp Neurol, 461, 394-413.

FAUST, P. L., BANKA, D., SIRIRATSIVAWONG, R., NG, V. G. \& WIKANDER, T. M. 2005. Peroxisome biogenesis disorders: the role of peroxisomes and metabolic dysfunction in developing brain. $J$ Inherit Metab Dis, 28, 369-83.

FAUST, P. L. \& HATTEN, M. E. 1997. Targeted deletion of the PEX2 peroxisome assembly gene in mice provides a model for Zellweger syndrome, a human neuronal migration disorder. J Cell Biol, 139, 1293-305.

FULLER, A. D. \& VAN ELDIK, L. J. 2008. MFG-E8 regulates microglial phagocytosis of apoptotic neurons. J Neuroimmune Pharmacol, 3, 246-56.

GAL, J. S., MOROZOV, Y. M., AYOUB, A. E., CHATTERJEE, M., RAKIC, P. \& HAYDAR, T. F. 2006. Molecular and morphological heterogeneity of neural precursors in the mouse neocortical proliferative zones. J Neurosci, 26, 1045-56.

GASPAR, P., CASES, O. \& MAROTEAUX, L. 2003. The developmental role of serotonin: news from mouse molecular genetics. Nat Rev Neurosci, 4, 1002-12.

GE, W. P., MIYAWAKI, A., GAGE, F. H., JAN, Y. N. \& JAN, L. Y. 2012. Local generation of glia is a major astrocyte source in postnatal cortex. Nature, 484, 376-80.

GERDES, J. 1990. Ki-67 and other proliferation markers useful for immunohistological diagnostic and prognostic evaluations in human malignancies. Semin Cancer Biol, 1, 199-206.

GOULD, E. 1999. Serotonin and hippocampal neurogenesis. Neuropsychopharmacology, 21, 46S-51S.

GUEROUT, N., LI, X. \& BARNABE-HEIDER, F. 2014. Cell fate control in the developing central nervous system. Exp Cell Res, 321, 77-83.

HATTEN, M. E. 1999. Central nervous system neuronal migration. Annu Rev Neurosci, 22, 511-39. 
haUbensak, W., ATtARDO, A., DENK, W. \& hutTNER, W. B. 2004. Neurons arise in the basal neuroepithelium of the early mammalian telencephalon: a major site of neurogenesis. Proc NatI Acad Sci U SA, 101, 3196-201.

HULSHAGEN, L., KRYSKO, O., BOTTELBERGS, A., HUYGHE, S., KLEIN, R., VAN VELDHOVEN, P. P., DE DEYN, P. P., D'HOOGE, R., HARTMANN, D. \& BAES, M. 2008. Absence of functional peroxisomes from mouse CNS causes dysmyelination and axon degeneration. J Neurosci, 28, 4015-27.

ITO, D., IMAI, Y., OHSAWA, K., NAKAJIMA, K., FUKUUCHI, Y. \& KOHSAKA, S. 1998. Microglia-specific localisation of a novel calcium binding protein, Iba1. Brain Res Mol Brain Res, 57, 1-9.

IWASHITA, M., KATAOKA, N., TOIDA, K. \& KOSODO, Y. 2014. Systematic profiling of spatiotemporal tissue and cellular stiffness in the developing brain. Development, 141, 3793-8.

JANSSEN, A., BAES, M., GRESSENS, P., MANNAERTS, G. P., DECLERCQ, P. \& VAN VELDHOVEN, P. P. 2000. Docosahexaenoic acid deficit is not a major pathogenic factor in peroxisome-deficient mice. Lab Invest, 80, 31-5.

KA, M., CONDORELLI, G., WOODGETT, J. R. \& KIM, W. Y. 2014. mTOR regulates brain morphogenesis by mediating GSK3 signaling. Development, 141, 4076-86.

KETTENMANN, H., HANISCH, U. K., NODA, M. \& VERKHRATSKY, A. 2011. Physiology of microglia. Physiol Rev, 91, 461-553.

KOBAYASHI, K., IMAGAMA, S., OHGOMORI, T., HIRANO, K., UCHIMURA, K., SAKAMOTO, K., HIRAKAWA, A., TAKEUCHI, H., SUZUMURA, A., ISHIGURO, N. \& KADOMATSU, K. 2013. Minocycline selectively inhibits M1 polarization of microglia. Cell Death Dis, 4, e525.

KOWALCZYK, T., PONTIOUS, A., ENGLUND, C., DAZA, R. A., BEDOGNI, F., HODGE, R., ATTARDO, A., BELL, C., HUTTNER, W. B. \& HEVNER, R. F. 2009. Intermediate neuronal progenitors (basal progenitors) produce pyramidal-projection neurons for all layers of cerebral cortex. Cereb Cortex, 19, 2439-50.

KREUTZBERG, G. W. 1996. Microglia: a sensor for pathological events in the CNS. Trends Neurosci, 19, 312-8.

KRYSKO, O., HULSHAGEN, L., JANSSEN, A., SCHUTZ, G., KLEIN, R., DE BRUYCKER, M., ESPEEL, M., GRESSENS, P. \& BAES, M. 2007. Neocortical and cerebellar developmental abnormalities in conditions of selective elimination of peroxisomes from brain or from liver. J Neurosci Res, 85, 58-72.

LAUDER, J. M. \& BLOOM, F. E. 1975. Ontogeny of monoamine neurons in the locus coeruleus, raphe nuclei and substantia nigra of the rat. II. Synaptogenesis. J Comp Neurol, 163, 251-64. 
LIAO, B., ZHAO, W., BEERS, D. R., HENKEL, J. S. \& APPEL, S. H. 2012. Transformation from a neuroprotective to a neurotoxic microglial phenotype in a mouse model of ALS. Exp Neurol, 237, 147-52.

LIU, Y., BJORKMAN, J., URQUHART, A., WANDERS, R. J., CRANE, D. I. \& GOULD, S. J. 1999. PEX13 is mutated in complementation group 13 of the peroxisome-biogenesis disorders. Am J Hum Genet, 65, 621-34.

LOIS, C. \& ALVAREZ-BUYLLA, A. 1994. Long-distance neuronal migration in the adult mammalian brain. Science, $264,1145-8$.

LUSKIN, M. B. 1993. Restricted proliferation and migration of postnatally generated neurons derived from the forebrain subventricular zone. Neuron, 11, 173-89.

MAGNUS, T., CHAN, A., GRAUER, O., TOYKA, K. V. \& GOLD, R. 2001. Microglial phagocytosis of apoptotic inflammatory T cells leads to down-regulation of microglial immune activation. J Immunol, 167, 5004-10.

MARIN, O. \& RUBENSTEIN, J. L. 2003. Cell migration in the forebrain. Annu Rev Neurosci, 26, 441-83.

MAXWELL, M., BJORKMAN, J., NGUYEN, T., SHARP, P., FINNIE, J., PATERSON, C., TONKS, I., PATON, B. C., KAY, G. F. \& CRANE, D. I. 2003. Pex13 inactivation in the mouse disrupts peroxisome biogenesis and leads to a Zellweger syndrome phenotype. Mol Cell Biol, 23, 5947-57.

MCARTHUR, S., CRISTANTE, E., PATERNO, M., CHRISTIAN, H., RONCAROLI, F., GILLIES, G. E. \& SOLITO, E. 2010. Annexin A1: a central player in the anti-inflammatory and neuroprotective role of microglia. J Immunol, 185, 6317-28.

MCGRATH, K. E., KONISKI, A. D., MALIK, J. \& PALIS, J. 2003. Circulation is established in a stepwise pattern in the mammalian embryo. Blood, 101, 1669-76.

MCKENNA, O., ARNOLD, G. \& HOLTZMAN, E. 1976. Microperoxisome distribution in the central nervous system of the rat. Brain Res, 117, 181-94.

MIGLIARINI, S., PACINI, G., PELOSI, B., LUNARDI, G. \& PASQUALETTI, M. 2013. Lack of brain serotonin affects postnatal development and serotonergic neuronal circuitry formation. Mol Psychiatry, $18,1106-18$.

MOLOFSKY, A. V. \& DENEEN, B. 2015. Astrocyte development: A Guide for the Perplexed. Glia, 63, 13209.

MULLER, C. C., NGUYEN, T. H., AHLEMEYER, B., MESHRAM, M., SANTRAMPURWALA, N., CAO, S., SHARP, P., FIETZ, P. B., BAUMGART-VOGT, E. \& CRANE, D. I. 2011. PEX13 deficiency in mouse brain as a 
model of Zellweger syndrome: abnormal cerebellum formation, reactive gliosis and oxidative stress. Dis Model Mech, 4, 104-19.

NAKAI, A., SHIGEMATSU, Y., NISHIDA, K., KIKAWA, Y. \& KONISHI, Y. 1995. MRI findings of Zellweger syndrome. Pediatr Neurol, 13, 346-8.

NGUYEN, M. N., CAVANAGH, B., DAVEnPORT, T., NORAZIT, A. \& MEEDENIYA, A. C. 2010. Tissue sectioning for epifluorescence microscopy, Spain, Méndez-Vilas,A., Díaz, J. (Eds.)

NICHOLSON, D. W., ALI, A., ThORnBerRY, N. A., VAILlANCOURT, J. P., DING, C. K., GALlANT, M., GAREAU, Y., GRIFFIN, P. R., LABELLE, M., LAZEBNIK, Y. A. \& ET AL. 1995. Identification and inhibition of the ICE/CED-3 protease necessary for mammalian apoptosis. Nature, 376, 37-43.

NISHINO, J., KIM, S., ZHU, Y., ZHU, H. \& MORRISON, S. J. 2013. A network of heterochronic genes including Imp1 regulates temporal changes in stem cell properties. Elife, 2, e00924.

NOCTOR, S. C., MARTINEZ-CERDENO, V., IVIC, L. \& KRIEGSTEIN, A. R. 2004. Cortical neurons arise in symmetric and asymmetric division zones and migrate through specific phases. Nat Neurosci, 7, 136-44.

NORAZIT, A., NGUYEN, M. N., DICKSON, C. G., TUXWORTH, G., GOSS, B., MACKAY-SIM, A. \& MEEDENIYA, A. C. 2011. Vascular endothelial growth factor and platelet derived growth factor modulates the glial response to a cortical stab injury. Neuroscience, 192, 652-60.

ONO, K., SHOKUNBI, T., NAGATA, I., TOKUNAGA, A., YASUI, Y. \& NAKATSUJI, N. 1997. Filopodia and growth cones in the vertically migrating granule cells of the postnatal mouse cerebellum. Exp Brain Res, 117, 17-29.

PARIDAEN, J. T. \& HUTTNER, W. B. 2014. Neurogenesis during development of the vertebrate central nervous system. EMBO Rep, 15, 351-64.

PARNAVELAS, J. G. 2000. The origin and migration of cortical neurones: new vistas. Trends Neurosci, 23, 126-31.

PARNAVELAS, J. G., ALIFRAGIS, P. \& NADARAJAH, B. 2002. The origin and migration of cortical neurons. Prog Brain Res, 136, 73-80.

PARNAVELAS, J. G., ANDERSON, S. A., LAVDAS, A. A., GRIGORIOU, M., PACHNIS, V. \& RUBENSTEIN, J. L. 2000. The contribution of the ganglionic eminence to the neuronal cell types of the cerebral cortex. Novartis Found Symp, 228, 129-39; discussion 139-47.

PAXINOS, G. \& FRANKLIN, K. B. J. 2001. The mouse brain in stereotaxic coordinates, San Diego, Elsevier Academic Press. 
POWERS, J. M. \& MOSER, H. W. 1998. Peroxisomal disorders: genotype, phenotype, major neuropathologic lesions, and pathogenesis. Brain Pathol, 8, 101-20.

POWERS, J. M., MOSER, H. W., MOSER, A. B., UPSHUR, J. K., BRADFORD, B. F., PAI, S. G., KOHN, P. H., FRIAS, J. \& TIFFANY, C. 1985. Fetal cerebrohepatorenal (Zellweger) syndrome: dysmorphic, radiologic, biochemical, and pathologic findings in four affected fetuses. Hum Pathol, 16, 61020.

POWERS, J. M., TUMMONS, R. C., CAVINESS, V. S., JR., MOSER, A. B. \& MOSER, H. W. 1989. Structural and chemical alterations in the cerebral maldevelopment of fetal cerebro-hepato-renal (Zellweger) syndrome. J Neuropathol Exp Neurol, 48, 270-89.

RAHIM, R. S., MEEDENIYA, A. C. \& CRANE, D. I. 2014. Central serotonergic neuron deficiency in a mouse model of Zellweger syndrome. Neuroscience, 274, 229-41.

RAKIC, P. 1985. Limits of neurogenesis in primates. Science, 227, 1054-6.

REZAIE, P. \& MALE, D. 1999. Colonisation of the developing human brain and spinal cord by microglia: a review. Microsc Res Tech, 45, 359-82.

ROWITCH, D. H. \& KRIEGSTEIN, A. R. 2010. Developmental genetics of vertebrate glial-cell specification. Nature, 468, 214-22.

SAKURAI, M., AYUKAWA, K., SETSUIE, R., NISHIKAWA, K., HARA, Y., OHASHI, H., NISHIMOTO, M., ABE, T., KUDO, Y., SEKIGUCHI, M., SATO, Y., AOKI, S., NODA, M. \& WADA, K. 2006. Ubiquitin C-terminal hydrolase L1 regulates the morphology of neural progenitor cells and modulates their differentiation. J Cell Sci, 119, 162-71.

SALEM, N., JR., LITMAN, B., KIM, H. Y. \& GAWRISCH, K. 2001. Mechanisms of action of docosahexaenoic acid in the nervous system. Lipids, 36, 945-59.

SARNAT, H. B., NOCHLIN, D. \& BORN, D. E. 1998. Neuronal nuclear antigen (NeuN): a marker of neuronal maturation in early human fetal nervous system. Brain Dev, 20, 88-94.

SCHAMBRA, U. 2008. Prenatal mouse brain atlas, New York, Springer.

SHIMOZAWA, N., SUZUKI, Y., ZHANG, Z., IMAMURA, A., TOYAMA, R., MUKAI, S., FUJIKI, Y., TSUKAMOTO, T., OSUMI, T., ORII, T., WANDERS, R. J. \& KONDO, N. 1999. Nonsense and temperature-sensitive mutations in PEX13 are the cause of complementation group $\mathrm{H}$ of peroxisome biogenesis disorders. Hum Mol Genet, 8, 1077-83.

SIERRA, A., ENCINAS, J. M., DEUDERO, J. J., CHANCEY, J. H., ENIKOLOPOV, G., OVERSTREET-WADICHE, L. S., TSIRKA, S. E. \& MALETIC-SAVATIC, M. 2010. Microglia shape adult hippocampal neurogenesis through apoptosis-coupled phagocytosis. Cell Stem Cell, 7, 483-95. 
STIPURSKY, J. \& GOMES, F. C. 2007. TGF-beta1/SMAD signaling induces astrocyte fate commitment in vitro: implications for radial glia development. Glia, 55, 1023-33.

TAMAMAKI, N., FUJIMORI, K. E. \& TAKAUJI, R. 1997. Origin and route of tangentially migrating neurons in the developing neocortical intermediate zone. J Neurosci, 17, 8313-23.

TAVERNA, E., GOTZ, M. \& HUTTNER, W. B. 2014. The cell biology of neurogenesis: toward an understanding of the development and evolution of the neocortex. Annu Rev Cell Dev Biol, 30, 465-502.

WICHTERLE, H., GARCIA-VERDUGO, J. M. \& ALVAREZ-BUYLLA, A. 1997. Direct evidence for homotypic, glia-independent neuronal migration. Neuron, 18, 779-91.

WILHELMSSON, U., FAIZ, M., DE PABLO, Y., SJOQVIST, M., ANDERSSON, D., WIDESTRAND, A., POTOKAR, M., STENOVEC, M., SMITH, P. L., SHINJYO, N., PEKNY, T., ZOREC, R., STAHLBERG, A., PEKNA, M., SAHLGREN, C. \& PEKNY, M. 2012. Astrocytes negatively regulate neurogenesis through the Jagged1-mediated Notch pathway. Stem Cells, 30, 2320-9.

WILSON, G. N., HOLMES, R. G., CUSTER, J., LIPKOWITZ, J. L., STOVER, J., DATTA, N. \& HAJRA, A. 1986. Zellweger syndrome: diagnostic assays, syndrome delineation, and potential therapy. Am J Med Genet, 24, 69-82.

WISNIEWSKI, T., POWERS, J., MOSER, A. \& MOSER, H. 1989. Ultrastructural Evidence for a Gliopathy in Cerebro-Hepato-Renal (Zellweger) Syndrome. Journal of Neuropathology and Experimental Neurology, 48, 366-366.

YAVIN, E., BRAND, A. \& GREEN, P. 2002. Docosahexaenoic acid abundance in the brain: a biodevice to combat oxidative stress. Nutr Neurosci, 5, 149-57.

ZECEVIC, N., CHEN, Y. \& FILIPOVIC, R. 2005. Contributions of cortical subventricular zone to the development of the human cerebral cortex. J Comp Neurol, 491, 109-22.

ZHAO, C., DENG, W. \& GAGE, F. H. 2008. Mechanisms and functional implications of adult neurogenesis. Cell, 132, 645-60. 


\section{Highlights}

- Altered brain anatomy and function in PEX13 brain restricted mice brains.

- Impaired neurogenesis, reduction in migration, differentiation, and maturation of neural progenitors particularly in serotonergic system in embryonic stages

- Exaggerated reactive gliosis and increased cell death. 